\title{
The Motifs of Eyes and Feet in Irish and Lebanese Poetry, Dance, and Caricature
}

\section{Resistance and Rebellion of the Suppressed Voice}

\begin{abstract}
Abir Ward
May $1^{\text {st }} 2010$

Thesis submitted in partial fulfillment of the requirements for a Master's in Comparative Literature

This thesis examines the cultural representation of traumatic memory. It assumes the existence of a "traumatic unsaid" that seeks expression by indirect means in art. In the case of the Irish and Lebanese cultural productions examined here, this thesis argues that artists repress painful emotions which find expression through displacement-a psychological defense mechanism in which there is an unconscious shift of emotions, affect, or desires from the original object to a more acceptable or immediate substitute - in the form of different motifs or symbols.
\end{abstract}




\section{"Crumbling between the fingers, under the feet, \\ Crumbling behind the eyes, \\ Their world gives way and dies}

And something twangs and breaks at the end of the street."

Louise MacNeice

Louis MacNeice once stated that "a poem in praise of suicide is an act of homage to life" (Heuser 138). If a poem is to be looked upon as "always positive" as MacNeice claims, then the term War Poetry becomes an oxymoron in which one word entails destruction and the other indicates creation even if only of an expressive voice or persona.

This expressive voice helps voice the trauma experienced as a result of war, and serves as an outlet to suppressed emotions caused by an oppressor. This unconscious manifestation of rebellion surfaces in the form of motifs in writing, dance choreography, and even caricature. It represents repressed emotional reactions to suppression.

In both Irish and Lebanese war poetry, pain, suppression, and destruction are prominent themes. A segment of these countries' poetry speaks about suffering and oppression experienced during and after the period of occupation and wars. However, the expression of rejection to the occupying power is not stated directly most of the time; resistance is expressed indirectly and rebellion surfaces through the use of several motifs. This thesis claims that such indirections result directly from oppression. As in the case of both Ireland and Lebanon which share similar history with oppression, their poetry, dance, and caricatures state a message of rebellion through images of eyes and feet and relevant motifs.

The political history of both Ireland and Lebanon involve occupiers who ruled for substantial periods of time. Lebanon endured a multitude of occupiers for hundreds of years, but the most prominent rule was that of the Ottoman Empire which extended from 1516 till 1920. France then colonized the country till 1943 when Lebanon gained an independence which has seldom been free of foreign intervention and which caused the country to fall into 
internal divisions and sectarian wars. In 1982, Lebanon was invaded by Israel during a gory civil war between Lebanese Christians and Muslims reducing the country into a bloody battlefield. Again, in 2006, Israel attacked Lebanon and destroyed its infrastructure. In spite its history with oppression and whether under the Ottoman, French, or Israeli occupations, Lebanese culture maintained its language and heritage marked by its oral folk poetry, zajal, and folk dance, Dabké.

Ireland, on the other hand, suffered from the suppression of its native Celtic tongue under more than four centuries of British rule. An island in the northern Atlantic Ocean, Ireland is divided between the independent Republic of Ireland and Northern Ireland, which is a part of the United Kingdom. Ireland was invaded by Celts c. 500 B.C. and later succumbed to English control in the 17th century. After the Easter Rebellion in 1916 and a war of independence (1919-1921) the island was split into the independent Irish Free State (now Ireland) and Northern Ireland, which is still part of Great Britain. After enduring English hegemony, economic devastations, civil wars, and internal sectarian conflicts, Ireland finally broke from the British Commonwealth in 1949. The decline, however, in the use of the Irish language occurred in the nineteenth century after the creation of the National School educational system and the ravaging famine of 1845 .

This thesis examines the cultural representation of traumatic memory. It assumes the existence of a "traumatic unsaid" that seeks expression by indirect means in art. In the case of the Irish and Lebanese cultural productions examined, this thesis argues that humans repress painful emotions which find expression through displacement - a psychological defense mechanism in which there is an unconscious shift of emotions, affect, or desires from the original object to a more acceptable or immediate substitute - in the form of different motifs or symbols.

This approach casts into relief how the rebellious Irish and Lebanese voices in poetry, dance, and caricature are created through repression and conveyed through the different 
motifs. From observation, I have found eyes and feet to be prominent motifs in these poems. Curiously enough, these motifs are often channeled aurally and not orally. That is to say, eyes in these poems "speak" and function in conjunction with the stomping and beating of feet. This thesis argues that this aural stimulation ensures a presence of a resistance force thus linking it directly to powerful rebellion.

In dance, this thesis will show how stomping motifs of Dabké represent an unavowed message of rebellion. Lebanese dance figurations are also done to the music and lyrics of sung poetry thus expressing better their rebelliousness as this thesis claims. Dance and poetry combined can better express this rebellious message.

Irish dance, on the other hand, is done to music without lyrics. Whenever words are being recited, the Irish dance stops. Interestingly, the largest gathering of sean-nós dancers occurs nowadays at "An Oireachtas na Gaeilge," an annual celebration of the Irish language. Irish language transferred its message of rebellion to dance. Irish dances represent the resistance and rebellion that the Irish seek to express if not in the language of their oppressors, through dances done in secret.

The Irish céilí [kāli] dance was invented in the late nineteenth century by the Gaelic League which selected various cultural practices to assert a cultural nationalism (Foley 35). The preservation of Irish music occurred as a response to the development of nationalist political consciousness and resulted in attributing symbolic emancipation to music (White 1). Though that conservation hindered artistic regeneration of this art in hopes of preserving the traditional, it led to the rise of particular Irish dances which use hard shoes. This interestingly coincides with the English suppression of the Celtic language in Ireland, and perhaps may be seen therefore as a displaced response. This thesis asserts that the forced suppression of the Celtic language gave rise to a bodily language, namely dance. In addition, the use of hard shoes implies a need to voice or vocalize more prominently this new form of language. 
In caricature, the Palestinian born cartoonist Naji el-Ali's drawings, which almost always show the oppressed as shoeless with broken or missing feet and the repressors or army men with heavy duty army boots, address a different kind of repressive control— that of the Israeli occupation of Lebanon.

Even in randomly selected Irish caricatures, eyes and feet represent oppression and resistance. The visual representation of repression is transferred once again from stage back to paper, but this time in the graphic method of caricature. Juxtaposed with Irish and Lebanese poetry and dances, caricature highlights the importance of this overlooked motif in the poetry of the repressed.

In the course of my research for this thesis, I travelled to Ireland in order to better acquaint myself with the nature of the country I was studying. The trip proved tremendously helpful for it introduced me to a culture very similar to the Lebanese culture. This emphasized my claim that those two cultures are similar because they have been subjected to similar turmoil.

Humans have always expressed themselves through indirections by using allegories, symbols, and images. Political repression occasions a particular kind of indirect aesthetic practice. Common image motifs in the artistic creations of two different cultures which have endured similar fates, but which do not share a language, significant history, or a common aggressor, might offer a more general understanding of how the repressed self articulates resistance. 
Motifs of Eyes and Feet in Irish and Lebanese Poetry

Ingeborg Bachmann once said: "With my burned hand I write about the nature of fire." Aside from the idea that the person who suffers dips his quill into pain and writes, this statement brings into light the image of the burned hand which, firstly represents the suffering of the writer, and secondly conveys an image of the physical pain this writer must be going through in order to carry out the mere act of writing. Add to that the concept of the part (the hand) representing the whole (the writer) which can encompass the life of the writer and his history of suffering. This body-part motif has been consciously chosen to represent and substitute other images and concepts in which the rebellious act of writing represents the resistance of the author. Whether understood at its literal level or as a symbol, the motif of the hand has played a double role: to tell of pain and to tell of rebellion.

This chapter starts with the claim that motifs of feet and eyes in Irish and Lebanese poetry are symbols of the suppressed voice of oppressed peoples. Other elements such as sight, dreams, visions on one hand, and footsteps, marching, rhythm on the other are subordinate motifs related to the main motifs of eyes and feet respectively. I have found a common motif which occurs alongside these motifs and subordinate motifs as well which should be also highlighted and tied to the over-all theme, and that is the short cycle of life which ends almost at its beginning. I will seek to explain how and why this idea might be linked to the motifs of eyes and feet and how it can be utilized to help understand their overall significance.

This chapter will seek to establish that these motifs are preconditioned by political oppression which directly leads to repression of voice which, in turn, finds an outlet through motifs. These motifs thus become symbolic representatives of acceptable rebellion whether the poem directly states it or not. Regardless of whether the poet seeks to make a statement or not, his/her motifs of eyes and feet become keys to understanding the act of censorship or suppression the author inflicts upon himself as he writes. 
After establishing the symbolic significance of these motifs through the study of Michael G. Levine's analysis of writing through repression and through Derrida's analysis of Freud's essays on repression, I shall then analyze three poems from each culture to highlight how motifs substitute voice in the face of oppression. These poems will be looked upon both as products of their political environment and as independent pieces of art in hopes of highlighting how these motifs, if understood as tools of expression, aid in understanding the psychological and the political significance of the poem.

Selecting Anglo-Irish and Lebanese poems regardless of their date suggests that these motifs are not time bound to a political incident, an economic upheaval, or even a language, but are rather rooted in the author's psyche and derive their significance from the fact that they might arise in poetry, dance, and caricature of any oppressed culture. I have used the Irish and Lebanese cultures in order to highlight how these motifs come to exist and how their symbolism extends beyond immanent images by studying poetry from two cultures with no geographical, historical, political, social, and cultural association.

What is significant about these motifs is not the frequency with which they occur, but rather the overall context in which they appear. Regardless of the morphological and etymological differences of feet and eyes in English and Arabic, there remains a very similar symbolic significance relevant to oppression and repression. They derive their symbolic significance from a psychological and political influence. Through this imagery, the poet devises a psycho-cultural construct to deal with trauma and oppression.

In veering away from Jung's idea of the collective unconscious, I've sought the winding road in proving that there need not be an unconscious bond between humans which leads to them producing similar art, but it is the human experience and reaction to oppression which can directly influence their representation of trauma through motifs linked to their bodies or their source of experience and expression. 
To establish how a traumatic unsaid finds its way into texts through indirection, I rely on Levine's Writing Through Repression in which he studies Derrida's reading of Freud and builds on it in order to better illustrate how writing occurs through repression. The concept of censorship, be it political or personal, conscious or unconscious, underlies most of Freud's studies of dreams and figurative language. This has sparked the interest of many such as Derrida, Borch-Jacobsen, Lacan, Benjamin, and many others who wrote on the subject. Levine utilizes their work in order to explain how writing should be studied vis-à-vis repression so that the former can be understood properly with all its implications.

To begin with, the censored or traumatized writer expresses via indirection what otherwise would "normally" appear directly in his writing. By relying on Levine's interpretation of Freud and Derrida, and by linking their work on repression to mine, I highlight how traumatic experience is registered in the conscious, gets thrown in the unconscious, tries to surface back to the conscious to no avail, then only succeeds in surfacing by attaching itself to an idea, thought, or image far removed from it in order to escape condemnation. Certain motifs are linked to this surfacing image, and act as a substitute to the original idea or event which was censored both externally and internally. Additionally, a few repeated images which appear in the poetry of the oppressed will be also connected to the stage which occurs before the surfacing of the motifs and which indicate a psychical disturbance caused by the censored idea trying to emerge from repression.

In order not to mix concepts up, it is important to clearly define oppression, suppression, and repression. While oppression is the exercise of cruel and whimsical power over other individuals, or the weighing down of one's body and mind, it is solely the exercise of power by one nation over another as pertinent to this study. Suppression, however, is "the conscious exclusion of unacceptable desires, thoughts, or memories from the mind" as defined in the American Heritage Dictionary. It can be exercised by the individual upon himself. Because Freud uses the term "repression" to mean both conscious and unconscious 
exclusion of thoughts from the mind though this mental activity that has been related to the unconscious, I shall highlight when the mental activity in question is conscious or unconscious where applicable. In this chapter, oppression will mean something inflicted by people upon others under their political rule, suppression will mean the conscious mental activity of keeping something away from the mind, and repression means the unconscious blocking of certain thoughts.

Repression is a reaction to suppression as relevant to this study. A poet does not have to experience trauma first hand in order to experience repression, but rather through his oppressed culture. His initial reaction, as described by Freud, would be flight. Since he cannot escape his cultural or societal trauma or that of his people, he internalizes it or keeps it out by letting it all in, i.e. repressing it as Levine states (76).

Levine adds that repression, initially, is a negative process suspended between passivity and condemnation. He explains that the "split temporality of censorship" has to do with the "displacement of a process which will have only taken place as pre- and/or postcensorship" (78). This repetitive action between passivity and condemnation when the repressed idea tries to make it out of repression but gets suppressed again causes certain motifs relevant to the internal conflict of writing to surface. They come about in the form of very short life cycle images which will be examined later on in the poems. This necessary aversion keeps these ideas away from an unconscious representation.

Repression, according to Freud, denies passage to some representations or puts off their connection to a substitute idea till later (Levine 82). However, repression isn’t solely about keeping away an unwanted idea but rather about finding a way to distort it so that it can find an outlet:

The fugitive cathexis attached itself to a substitute idea, which on the one hand, was connected by association with the rejected idea, and, on the other, escaped repression by reason of its remoteness from that idea (displacement-substitute), and which permitted of a rationalization of the still uncontrollable outbreak of anxiety. (85) 
As such, traumatic experience related to oppression finds an outlet by attaching itself to a substitute idea related to it yet remotely associated with it. After an elaborate analysis of Freud's corpus, Levine simply explains that the idea finally finds an outlet through cathexis or the concentration of emotional energy on an object or an idea. This substitute representation, as Levine calls it, wavers "between mere appearance and actual existence since it first adopts the role of "playing a part" then "being or acting as if it were" (85).

Therefore, the motifs of feet and eyes represent a traumatic unsaid which attaches itself to this picture or representation in order to escape oppression and repression on the one hand, and to express rebellion on the other. From empirical observation, I have found eyes and feet to be prominent motifs in these poems. Eyes assume different roles and ensure a presence of a rebellious force linking them directly to power struggle.

In his poem "To the Rose Upon the Rood of Time," Yeats addresses the rose of eternity upon the cross of time as explained in the footnotes of the text. The word rose is capitalized to allude to the rose of time and not a mere flower:

To the Rose Upon the Rood of Time

Red Rose, proud Rose, sad Rose of all my days!

Come near me, while I sing the ancient ways:

Cuchulain battling with the bitter tide;

The Druid, grey, wood-nurtured, quiet-eyed, Who casts round Fergus dreams, and ruin untold; And thine own sadness, whereof stars grown old In dancing silver-sandalled on the sea, Sing in their high and lonely melody. Come near, that no more blinded by man's fate, I find under the boughs of love and hate, In all poor foolish things that live a day, Eternal beauty wandering on her way.

Come near, come near, come near-Ah, leave me still

A little space for the rose-breath to fill!

Lest I no more hear common things that crave; The weak worm hiding down in its small cave, The field-mouse running by me in the grass, And heavy mortal hopes that toil and pass; But seek alone to hear the strange things said By God to the bright hearts of those long dead, And learn to chaunt a tongue men do not know. Come near; I would, before my time to go, 
Sing of old Eire and the ancient ways:

Red Rose, proud Rose, sad Rose of all my days.

1892

The poet uses the symbol of the Rosicrucian order, a brotherhood which originated in the seventeenth century and is devoted to the study of the ancient mystical and religious doctrines, and applying them to modern life (The American Heritage Dictionary).

Conventionally, the rose stands for eternity while the cross stands for time. The poet longs to sing the ancient ways because by going back to the roots and getting rooted knowledge, he can grow. Yeats, as a poet, didn't succeed in learning the Irish language. During his time, there occurred a movement to go back and master the Celtic tongue, and the debate about what is to be considered Irish literature was very heated.

To go back and sing of the ancient ways, one had to master the Irish language like John Millington Synge did. Yeats's attempts to refer to myths was scorned because his knowledge of the Celtic tradition came through translations and not first hand (Kiberd, 56). Interestingly, words such as "chaunt a tongue" renders the syntax strangely felt in the mouth while being recited as if one is truly learning a new language. Such a sensibility in the poem places heavy emphasis on how the poem is felt in addition to being read and understood.

Would going back to the old ways bring wisdom upon its seeker? The speaker refers to King Fergus McRoy who begs the Druid to allow him to open his "bag of dreams" and see all his previous lives. When he becomes knowledgeable, he sinks into despair (Kiberd, 31).

In the poem, the Druid is described as grey, wood-nurtured ${ }^{1}$, and quiet-eyed. The adjective "quiet" used to describe the eyes means awake, still, and unmoving, unlike the rapid-eye movement which refers to the stage of dreams between the state of cognizance and that of sleep. The Druid isn't asleep but rather awake and knowledgeable. In spite of his knowledge, the Druid does not warn Fergus of what might befall him. He can see but remains

\footnotetext{
${ }^{1}$ In Celtic mythology, the druid is also known as the "oak-seer" or "oak-knower" in reference to a ritual supposedly exercised by druids in pagan Ireland (Encyclopedia Britannica Online). This is probably why Yeats refers to the druid as "wood-nurtured."
} 
quiet. "Quiet eyes" correspond to "ruin untold" in the line which succeeds it since these actively observing eyes remain silent. His quiet eyes correspond also to his quiet tongue for he discloses to Fergus his bag of dreams without telling him that knowledge might leave him despairing. The knowledge of his past life left him drained though it bestowed wisdom upon him.

The image of the stars dancing silver-sandalled on the sea while singing their lonely song contrasts with the image of silence in previous lines and the disclosed truth through visions and dreams. The shifting of images from silence to song and from quiet eyes to singing silver sandalled correspond to the choice of going back to the roots and learning how to sing about the ancient ways. The Irish language which was suppressed around the eighteenth century regained its momentum early twentieth century and drove poets to try to learn it in hopes of strengthening their link with their perceived cultural origins.

The first stanza concludes with the speaker telling the Rose that he is no longer "blinded by man's fate" and finds under "the boughs of love and hate" eternal beauty lying in the most simple of things. What man thinks of as deep emotions (namely love and hate) and regards with awe for being man's fate (namely death), the poet regards as blinding. "The absence of vision is a source of bewilderment" states Santanu Das especially when "men navigate space not through reassuring distance of the gaze but through the tactile immediacy of their bodies" (75). To lose sensibility means loss of utter perception and the ability to feel and thus love and hate, but to the poet, it means liberation of "heart." To be able to dance with feet in the sand and eyes on the stars thus corresponds to complete liberation.

The second stanza contains an image which again presents a contrast between what runs easily and what moves laboriously. The speaker describes the beauty in the simple things in nature such as the field-mouse running past him in the grass, then talks about "heavy mortal hopes that toil and pass." The image of the running mouse contrasts with the 
image of mortal hopes which are described as heavy and which pass laboriously. Hopes become heavy and weigh a person down in senses or spirit exactly like oppression.

The speaker then describes the hearts of those long dead as being "bright" thus alluding that they might be more alive than the living. Their state is that of awakening since they can hear "the strange things said/By God." The speaker wishes to learn how to chant songs of old Ireland before he dies and concludes with the necessity to go back and learn how to speak of the old ways and of one's roots in order to be heard. To relearn one's mother tongue means being able to vocalize oneself clearly.

The Valley of the Black Pig

The dews drop slowly and dreams gather: unknown spears

Suddenly hurtle before my dream-awakened eyes, And then the clash of fallen horsemen and the cries Of unknown perishing armies beat about my ears.

We who still labor by the cromlech on the shore,

The grey cairn on the hill, when day sinks drowned in dew, Being weary of the world's empires, bow down to you, Master of the still stars and of the flaming door.

1899

Yeats explains the significance of "The Valley of the Black Pig" as follows: "The Irish peasantry have for generations comforted themselves, in their misfortunes, with visions of a great battle, to be fought in a mysterious valley called, 'The Valley of the Black Pig,' and to break at last the power of their enemies" (33). To dream of a battle in which one conquers an enemy helps the oppressed with his mental preparation for rebellion. The connection between eyes and images on one hand, and images and knowledge on the other, renders dreams, visions, and consciousness fused where a distinction between what is real and what is not becomes unnecessary.

The image of "dream-awakened eyes" in line two suspends the reader between two images: that of eyes awakened from a dream, and that of eyes awakened by a dream. Since the entire poem speaks of a dream battle in which the Irish peasantry used to solace themselves, the two ideas of whether the speaker is being awakened to a dream or by a dream remain equally plausible. 
If the speaker means getting awakened by a dream, then the poem means that this dream of victory which has been revived generation after generation, has become a collective consciousness for the Irish. Its repetition has awakened the speaker to the importance of this battle which gives people hope and stamina. To be able to dream of accomplishing a victory helps give ample hope to those who have endured misfortunes.

On the other hand, if the term "dream-awakened eyes" means getting awakened to a dream, then it could mean to die and go to paradise where the people of the speaker finally fight and conquer their enemy. The last four sentences of the poem assert this idea since they speak of those "weary of the world's empires," especially the British Empire, bowing down to the Master of the stars and the flaming door or, in other words, their savior. The cromlech and the cairn are prehistoric Celtic tombs which are spread around Ireland. Both foreshadow the death of the speaker with the image of the sinking day in line six. Nevertheless, those Celtic tombs are surviving testaments to the existence of this land before Catholicism and assert the Celtic identity of the people which endured centuries of British rule.

The mind might be left unaware of what is real and what is a dream, but this mix of dreams, visions, and consciousness is the poet's attempt to put into words a battle his people have dreamt of fighting for centuries. Benjamin might refer to this as a "phantastic combat" in which the poet draws himself as a combatant parrying his own blows, engaged in a "spectral duel" or shadowboxing which acts as a shock defense (Levine 106-109). It helps him deal with a trauma endured by his people by representing their experiences from the first person. Whether death is a state of dream or a reality which supersedes life remains unclear in the poem, but eyes remain the tool of registration of images in both states.

“The Albert Chain” by Medbh McGuckian from 1994 speaks about the conflict in Northern Ireland. Kieth Tuma states in the footnote of the poem that "McGuckian's father's second name was Albert, a very British name; thus for her it was a kind of "chain." "In a letter McGuckian notes of the image of the chain: 'The whole first stanza circles around that 
theme. Something at the end of something else - the imperial legacy of Northern Ireland. We are still bound to Victorian England which no longer exists except here"” (Tuma 788):

Like an accomplished terrorist, the fruit hangs

from the end of a dead stem, under a tree

riddled with holes like a sieve. Breath smelling

of cinnamon retires into its dream to die there.

Fresh air blows in, morning breaks, then the mists

close in; a rivulet of burning air

pumps up the cinders from their roots,

but will not straighten in two radiant months

the twisted forest. Warm as a stable,

close to the surface of my mind,

the wild cat lies in the suppleness of life,

half-stripped of its skin, and in the square

beyond, a squirrel stoned to death

has come to rest on a lime tree.

I am going back into war, like a house

I knew when I was young: I am inside,

a thin sunshine, a night within a night, getting used to the chalk and clay and bats swarming in the roof. Like a dead man attached to the soil which covers him, I have fallen where no judgment can touch me, its discoloured rubble has swallowed me up.

For ever and ever, I go back into myself:

I was born in little pieces, like specks of dust, only an eye that looks in all directions can see me.

I am learning my country all over again, how every inch of soil has been paid for by the life of a man, the funerals of the poor.

I met someone I believed to be on the side of the butchers, who said with tears, 'This is too much.' I saw you nailed to a dry rock, drawing after you under the earth the blue fringe of the sea, and you cried out 'Don't move!' as if you were already damned. You are muzzled and muted, like a cannon improvised from an iron pipe. You write to me generally at nightfall, careful of your hands, bruised against bars: already, in the prime of life, you belong to the history of my country, incapable in this summer of treason, of deliberate treason, charming death away with the rhythm of your arm.

As if one part of you were coming to the rescue of the other, across the highest part of the sky, in your memory of the straight road flying past, I uncovered your feet as a small refuge, 
damp as winter kisses in the street, or frost-voluptuous cider over a fire of cuttings from the vine. Whoever goes near you is isolated by a double row of candles. I could escape from any other prison but my own unjust pursuit of justice that turns one sort of poetry into another.

The poem opens with an odd simile between an "accomplished" terrorist and a fruit hanging from a dead stem. The word "terrorist" was originally applied to the supporters of the Jacobians in the French revolution who used violence to attain "democracy" and "equality" (Oxford American Dictionary). Though the dead tree is riddled with holes as if from machine gun shots, it bears fruit. Hence, the terrorist who allegedly terrorizes for the greater good, inflicts destruction.

The images of life ending immediately after it begins mark the first stanza with images of dead things such as a tree, a cat, and a squirrel. As mentioned in the first part of this chapter, repression starts as a process swinging between passivity and condemnation, and this repetitive action symbolizes the internal conflict with a repressed idea trying to get represented. This struggle with representing a repressed idea surfaces in the form of images of birth followed by imminent death.

Layered with those images are the ideas of dream and the surface of the mind which allude to a struggle between the consciousness and the unconsciousness and seek to escape censorship by representing a death wish. In line four, the image of the breath smelling of cinnamon is followed by the dream of dying at that particular spot. If "breath" alludes to the presence of a human inhaling and exhaling, then this human retired at that particular spot wishing to die just there. However, "breath" can also mean spirit or vitality and therefore the image of death following the image of breath becomes more inclusive to mean any spirit yielding to death or even wishing it upon itself. In both instances, death is called for. Lines nine and ten then state: "Warm as a stable,/close to the surface of my mind" and allude to a 
state of rest in which the subconscious perceives. Writing here becomes a moratorium: a suspension between active rebellion and a succumbing to death. However, it acts against itself because writing, after all, is a creation of a voice.

The second stanza also starts with a simile between war and a house known to the speaker since childhood. The familiarity of the house signifies the familiarity of war to the senses of the speaker. The images which come afterwards speak about what is being encompassed. Images of the within such as "I am inside," "a night within a night," "the soil which covers him," and "I go back into myself" all allude to the longing to a place safe from harm - a womb. To go back to the inside means to search for some answers or simply comfort and safety.

Additionally, the images of death and burial stand out. To be buried, however, seems to distance the speaker from harm: "Like a dead man/ attached to the soil which covers him./I have fallen where no judgement can touch me.” The speaker tries to evade judgement inflicted upon her not by God but by what might be distancing her from her land. To be attached to the soil which covers her means to be almost disintegrated and beyond grasp.

This image of disintegration in the final part of the second stanza presents an image of parts which make up the whole ("I was born in little pieces, like specks of dust"), similar to the dissipation of rebellion of the oppressed. Voice is disintegrated and buried. The only "eye" which can see the parts as a whole is an eye "that looks in all directions": The allknowing - that of the creator. This omniscient eye resides in the inside of the speaker and not only sees in all directions, but probably from every standpoint. The speaker decomposes the image, then presents the only thing that can see everything whole. This eye is also a part of a whole, yet it can stand on its own because it is the first organ which perceives and stores information which does not necessarily make it past perception. Cathy Caruth's Unclaimed Experience: Trauma, Narrative, and History explains how experience of trauma prohibits one from believing what one is seeing and so most of it gets stored in the eyes and does not 
make it in and may be adjusted after a while to fit the picture in mind. Thus, it is necessary for the speaker to destruct the image, present it in pieces, then construct it in a way to fit the overall image in the mind. This way, the eye remains as the omnipotent organ in which all experience, whether later expressed and articulated or not, is stored.

Though the final part of the second stanza ends with the image of death yet again, it also alludes to the speaker's renewed appreciation of her land which was foreshadowed earlier in line 20 when she compares herself to a dead man attached to the soil with which she is covered. Here, the emergence of nationalism or being attached to one's country marks a shift in the poem. Occurring after the image of the eye, the speaker finally uses a positive term "learning" unlike terms which preceded it such as "Going back," "fallen," and "born in little pieces." The "I" in the final stanza is "learning" about its country all over again, and learning about how expensive it has been to protect it.

It is no coincidence that the image of the "eye" was followed by the concept of "learning." To see means to know for sight is associated with wisdom which is referred to by the inner eye. It can be a sense organ, or it can be directed inwards. Interestingly, the speaker, who is not necessarily an "eye" witness to all the atrocities committed against her people, speaks in the first person as if she is directly experiencing, all over again, what her country has passed through in order to preserve its independence. The "I" therefore, represents the whole through the omniscient "eye."

After the "I" establishes itself as the representative of the whole in the second stanza, it engages in a one-sided dialogue with a "you" who represents the butcher, the terrorist, or the enemy. The butcher, with tears signifying regret in his eyes, is overwhelmed with the situation. Jo Gill links this image to the legend of Prometheus who was punished by Zeus for giving humans fire. Zeus chained Prometheus to a rock and sent an eagle to eat his liver which grew back daily. Gill suggest that this image represents "ceaseless punishment and despair" yet might allude to temporary resolving of tension be it historical, political, or 
cultural (176). However, I believe that the "chain" binds the speaker to the history of slavery imposed upon her people by the colonizers, all while referring to the endless link between life and death or the "living death" of the oppressed. Hence, the circle of the chain refers to the short cycle of life which ends immediately after it begins, reminding the oppressed of their history of oppression, and linking this history to that of their oppressors: "already, in the prime of life, you belong/to the history of my country ..."

The motifs of "muzzled" and "muted" in the fourth stanza reverse the roles between oppressor and oppressed. Here, the butcher or terrorist is muzzled and muted, nailed to a rock, damned, and placed behind bars. The speaker states that the enemy writes to her in order to delay his death. He is motionless, confined, and unheard. As if the chain which binds the oppressed to the oppressor has confined the latter to the first. Interestingly, it can be said that the speaker, in her lively death, is dreaming of being the audible while the oppressor is muzzled. Audibility strengthens the position of the oppressed since it renders her heard.

The speaker plays the role of liberator in the final stanza in order to liberate herself. The hand of the oppressed liberates the foot of the oppressor in line 45, and by doing so, she helps the oppressed gain some of his power back. To put one on his feet is to help him support himself. The foot motif here represents a wish to be able to stand on one's feet and to regain or have some control, and by liberating her enemy from the chain binding both and weighing them down, she does liberate herself.

The final stanza ends with what might probably be a reference to terrorist acts committed by the IRA in order to reunite the North with the South. As it turns out, the terrorist's acts are unjust to those harmed during this pursuit of justice. However, if the terrorist is a liberator, a liberator is also a terrorist. By claiming the role of the terrorist and liberating him, the speaker breaks the "Albert" chain or the English chain binding the Northern Irish to England. 
Lebanese zajal is a form of improvised poetry popular in the Near East and is entirely in colloquial or vernacular Arabic. According to Pierre Cachia, zajal originated in Spain as a descendant of muwashshah, and then spread to other parts of the Arab world (37). He adds that it is entirely an Andalusian vernacular (91). According to Michel Jeha, zajal started prospering in Lebanon over five centuries ago, but became very popular in the $20^{\text {th }}$ century and especially in villages in Mount Lebanon where zajal poets were numbered in the hundreds if not more (32). Cachia mentions "the seven arts" which constitutes the different types of zajal but admits to the presence of more subdivisions which Amin el-Qari lists as twelve in his book Rawa'e el-Zajal al-Lubnani (The Marvels of Lebanese Zajal) which include thirteen sub-divisions of the quirrādi alone.

Zajal is drafted for recital. It is written for the purpose of being spoken. The words of a zajal poem fall on the paper in the same way it would be spoken with little regard to adhering to the rules of fusha or standard Arabic. Its spontaneity renders it closer to the ear and eye of a listener or reader. However, if writing is more reflective than talking, then written zajal combines the poise of writing and the unceremoniousness of speech.

The first poem presented here was written by Khalil Sarieddine in the wake of the civil war which started in 1975 and ended fifteen years later after politically tearing the country apart. The poem, published in 1999 in Sarieddine's zajal bila wajal (zajal without fear), had been in the poet's collection for years before its publication. The aftermath of the war, still felt today, left the Lebanese people exhausted and more inclined to blame others for their disputes then blame themselves.

The translated poem does not do justice to the measured rhyme and rhythm of the poem but gives an idea of the overall subject. The poem goes as follows:

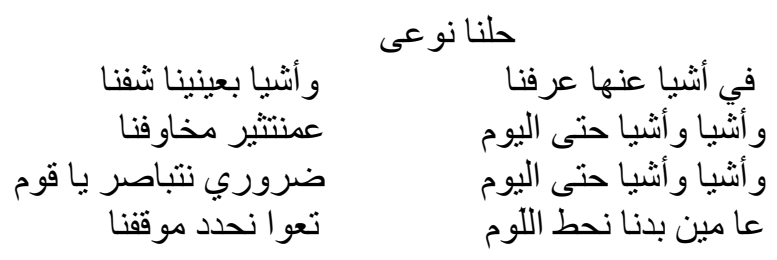




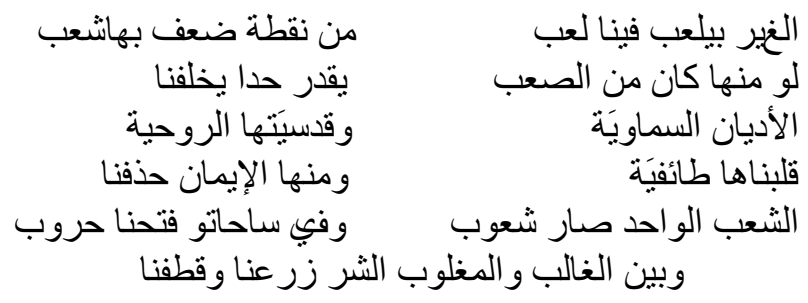

It's Time We Wake Up

There are things we knew about

And things we saw with our eyes,

And things and things until this day

Galvanizing our fears.

Things and things until this day,

It's important to visualize,

Know who to blame;

Let us define our status.

Others toy with us

Out of weakness on our behalf;

Had it not been for that

It would have been very difficult to divide us up.

We turned Religions

And its spiritual sacredness

Into sectarianism

And cancelled faith out of it.

One people became many people

And waged wars in their yards.

Between the defeater and the defeated

We planted and harvested evil.

In Sarieddine's poem, the speaker breaks the silence after being an eye witness to war's monstrosity. He points to his and his people's fear of what the war has led them to. The title "It's Time We Wake Up," could carry two meanings in its folds since "نوعى" in colloquial means both to wake up and to come to a full realization of a truth. Again, to be asleep alludes to being ambivalent to a truth, and therefore, upon awakening or opening one's eyes up “يفتح عيونو” one attains a state of comprehension.

Upon waking up, the speaker calls for a reaction towards what has been dividing the Lebanese on the basis of sectarianism. The poem begins with the knowledge associated with seeing. Sight, connected with perception and thus knowledge, sets the tone to the rest of the poem. However, with knowledge comes fear primarily because of the grossness of a war which turned religions into division categories. 
Vision, in line six, defines responsibility for the speaker states clearly that it is important to know who to blame for the mishaps of society. Others, namely foreign enemies regardless of their nationalities, toy with this society by dividing it into sectarian-based political fronts. According to the poet, divisions have occurred because people seem ambivalent to what others are doing to them. Here, others can be defined as intruders who have found it easier to break the resistance of a certain people by dividing them up thus asserting the popular saying "فرق تسد" (divide to conquer). However, the speaker states that had it not been out of weakness on the behalf of his people, it would have been impossible for the enemy to divide them up. Weakness, associated with lack of knowledge, indicates that to be blind is to not know, and to not know is to be weak.

Blindness doesn't allude to the disability of the sense of sight but rather means the absence of internal wisdom in human beings. The image registered in the mind and memory gets taken in by the eye first and therefore, the motif of the eye represents the first encounter with the thought itself. However, the eye, as a motif, is so far removed from the idea which is usually shunned from the conscience that the rejected idea forms a cathexis to it in hopes of escaping repression.

Symbols of "vision" vis-à-vis "savior" take a prophetic meaning in the poem though not in a blasphemous manner. In the second part of the poem, the speaker assumes the role of the savior and addresses the issue of religion and sectarianism even more directly. He states that faith has been cancelled out of religions which are turned into grounds of political conflict. Finally, the speaker assumes a role bigger than being a member of the oppressed people. In the final lines he states that he and his people planted and harvested evil between the defeater and the defeated. The speaker, like in "The Albert Chain," takes on a greater role that a mere speaker and claims responsibility of alienating the defeater and the defeated by, probably, spreading the knowledge of his vision. By knowing the plan of the defeater, the speaker was able to instruct. 


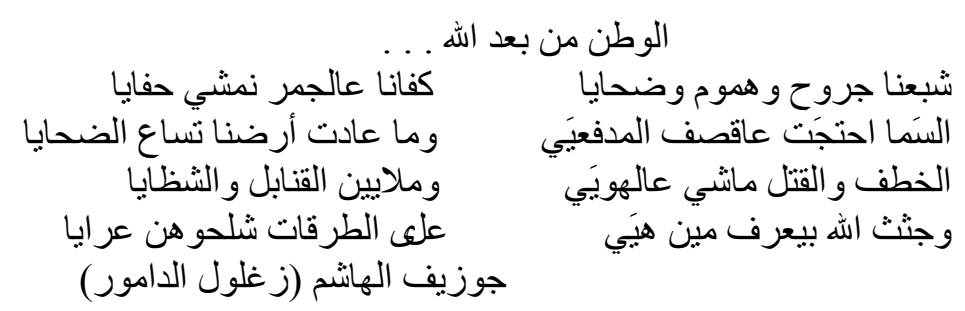

The Nation after God

We're fed up with wounds and worries and casualties,

Enough walking barefoot on hot coals.

The sky complained about the firing of cannonballs

And earth cannot accommodate all the casualties.

Kidnapping and killings based on the identity card

And millions of bombs and splinters

And corpses even God cannot identify

Strewn naked on the streets.

Joseph al-Hashem, known in the zajal circles as Zaghloul e-Damour, remains till date one of the most recognized names in improvised Lebanese zajal. His poem "The Nation after God" presents a glimpse to the suffering of the people in the war's aftermath and was probably written in the eighties in reference to the Civil War judging by the content.

To begin with, the image of "walking barefoot on hot coals" summarizes a situation in which the survivor tries to move forward in life away from pain and war but finds it as difficult as walking on hot coals. To intensify the image, the speaker walks "barefoot" signifying powerlessness. To be wearing shoes symbolizes protection against splinters and pebbles. They empower and enable their wearer. As mentioned in the caricature chapter, shoes imply power while shoeless implies helplessness and weakness. Atrocities here are not experienced through eyes but rather through feet.

The image of hot coals condenses numerous experiences and emotions into one symbolic image. Because it can portray the image exactly while being immune from carrying a precise symbolic reference, it escapes censorship. Freud explains that the author is one who "has contented himself with approximations and allusions to what would genuinely have come from his pen." Hence, displacement is used in order to strip the original idea of its intense psychical disturbances, and then condenses it through overdetermination to create images of intense psychical value out of elements of low psychical value (Levine 28-29). 
The sky and earth corroborate the speaker's stance by complaining about the cannonballs and the overwhelming number of casualties, and the bombs and splinters constitute the components of these symbols and contribute to the entire image: earth and sky separated with bombs, splinters, dead bodies, and flying cannonballs. The space of war extends beyond national borders to include the heavens and earth, and even God is rendered helpless and cannot identify all the naked corpses strewn on the street. This image elevates the stance of the speaker who takes charge and asks for a cessation of the war by saying "we are fed up." Richard Hugo once remarked: "voice is usually something that grows out of stance. It has to do with how strong a person's urge is to reject the self and to create another self in its place" (110).

Levine states that "the experience of shock could only be described from the outside" (106). If an experience of a shock can best be described by another or one can only talk about it directly when he is describing it as if it had occurred to someone else, then it might be plausible to claim that the reverse is true. One can only make an event which did not happen with him seem realistic and plausible if one speaks of it as if it had happened to him. This separation between the self and the other or the fusion between the other and the self invite creativity and role-play which in turn invites dream thoughts. Many ideas are repressed to allow other ideas to surface, and therefore a lot of imagination or thoughts beneath the surface of the mind become mixed up with what is real and what is not. This wouldn't rule out the presence of cathexised motifs in poems of the repressed because a cultural experience can have its traumatizing effects on any member of that culture or community.

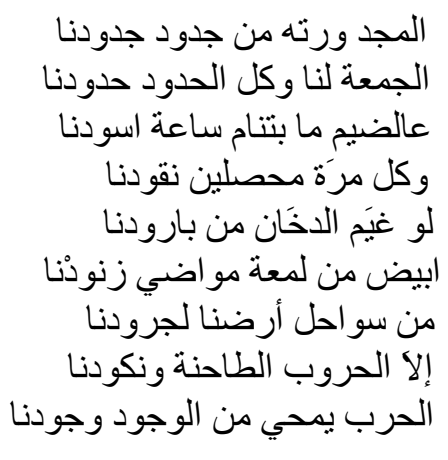
سلاح العيون 


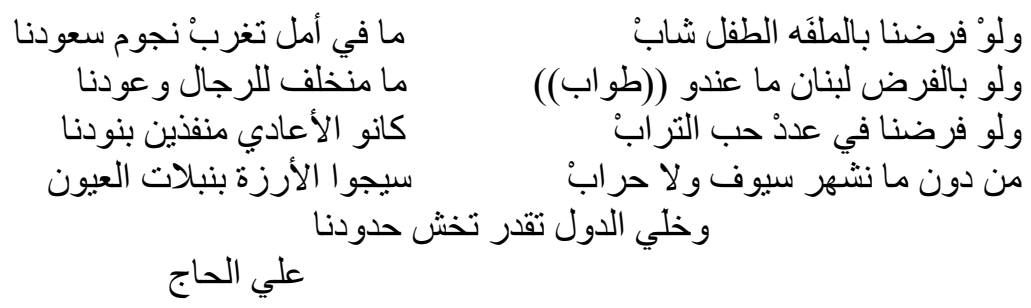

The Weapon of Eyes

We in Mount Lebanon who can rule us?

We inherited glory from our great grand fathers

And we've written a book about the love of nation;

The gathering is ours and all the borders are ours.

On the battle day we gather-young and old;

Our lions never overlook injustice.

We submerge ourselves in the torrential sea of battles

And get our pay for it every time.

Two weeks ago I saw people basking in doubt

From the seashore all the way to our deserts,

And no dialogue among them nor answers

Except for peevish wars;

News which scared even the hero.

War erasing our existence from existence.

If we assume the infant became grey in his swaddle,

Then there is no hope that our lucky stars would evanesce.

And even if Lebanon, by assumption, does not have a remedy,

We won't rebut our promise to men.

And even if enemies were as abundant as sand granules,

Without even raising swords or arrows,

Fence the cedar with the arrows of eyes

And dare nations to invade our borders.

Ali el-Hajj was born in 1900 and witnessed in 71 years the dissolving of the Ottoman

Empire and the colonization of Lebanon by France. Though the exact date of his poem is

unavailable, it was probably written after Lebanon gained its independence in 1945.

The poem's title contributes volumes to the motifs of eyes. It begins with a challenge

to any invader who threatens to rule, and tells of a glory inherited over generations. The

speaker then speaks of borders which are protected by the young and old who would engage

in any battle with no fear. After describing those self-righteous people, the poet then

introduces the image of conflict between these people but does not express the idea of war

graphically like we've seen in other poems; he simply describes it as "peevish wars." The

speaker then immediately jumps to the remedy as if ridden by guilt because of this war which

the reader then concludes was caused by a foreign enemy and not from within. The poet then 
resorts to protecting the cedars, the symbol emblazoned on the Lebanese flag and the pride of the Lebanese people, with the arrows of eyes instead of swords.

The image of the infant turning grey in the swaddle fits into the image of immediate death following birth and thus into the circle of repressed idea swinging between the conscious and the unconscious. "If representation can be shunted aside, excluded from consciousness," states Samuel Weber, "this can occur only by means of another representation taking its place" (40-41). The poet struggles with the thought of hopelessness for Lebanon especially since political analysts have been repeating for decades that the Lebanese political situation has no true remedy and that the combustive political situation is always on the verge of a renewed war, and so this hopelessness surfaces in the form of this short life cycle which finds indirections through images such as the above mentioned one. Nevertheless, this reference to death is reversed when the speaker retaliates against this thought and, again, plays the role of the savior by suggesting ascension above the enemy metaphorically especially since the cedars grow on the highest peaks of the Lebanese mountains.

The poem culminates in its ending. In the absence of arms, voice, and destruction, when wars and battles fail at liberating the land, the speaker brings forth the last and strongest form of defiance - that of the eyes. To protect or serve with one's eyes “ بحميك بخدمك او بحطل "بعيوني is a familiar expression in colloquial Arabic. It indicates the highest form of honoring to another. As Barbara Herrnstein Smith states in her book Poetic Closure, this "sense of truth" which "when it occurs at the conclusion of a poem, strengthens or secures the reader's sense of finality and stability" (154).

Robert Philips states: “A true confessional poet places a few barriers, if any, between his self and direct expression of that self, however painful that expression may prove" (8). Nevertheless, placing barriers is only human especially when it comes to voicing rebellion against an oppressive force. 
If "writing is the destruction of every voice, of every point of origin" as Roland Barthes once wrote (o.c.), then the writing of poetry by an oppressed culture is the creation of a voice from a void point of origin which is the repressed idea. By seeking to study the psyche of the poets who produced the poems selected above and by not paying due attention to the author's life outside the political context of his/her national belongingness, I've sought to establish that motifs arise to voice rebellion against oppression in the form of eyes and feet. Space non-permitting, I selected only three poems of each culture in order to demonstrate how such motifs exist and mean the same in cultures remotely associated politically, socially, linguistically, and culturally.

In the Lebanese culture, the saying "قعد اعوج واحكي جالس") (sit crookedly but speak straightforwardly) indicates that the Lebanese have less of a problem expressing themselves in a language that is theirs. Nevertheless, a history laden with invasions and control left the Lebanese keener on expressing themselves in oral poetry improvised on occasion. Still, images of eyes and feet surface in their war poetry leaving little doubt as to how repression does not have to be solely of a language. To express to a beloved one the desire to hide her in one's eyes in colloquial Arabic arises from the fact that many oppressed groups in Lebanon lived in hiding in Mount Lebanon for centuries. If no other hiding place is found, the lover would hide his beloved in his eyes. The imagery in the Anglo-Irish poems is vivid and pronounced, but the Lebanese zajal poets seem less bent on using symbolism and allude to facts more straightforwardly. Their language was never suppressed and they do not speak the language of their oppressors. Instead, they have maintained a language of their own regardless of the amount of borrowing from their colonizers which they have done.

On the other hand, the Irish used, as Françoise Meltzer would put it, "a language of invasion, colonization, and expropriation ... to describe their struggles" (Levine 9). This posed a big problem for the Irish because they fought a war with the weapons of their enemies. As Declan Kiberd states: “All through the nineteenth century, Irishmen had fought 
and argued for the freedom of their country while, at the same time, they permitted the virtual extinction of the native language and culture - a major basis of their claim to recognition as a separate nation" (57). Thomas Kinsella best describes this dilemma by stating that "An Irish poet has access to the English poetic heritage through his use of the English language, but he is unlikely to feel at home in it ... for more than a hundred years, there [was] almost total poetic silence" (5). This alienation of a medium of expression yields to repression of inexpressible ideas and feelings which find approximations through motifs. A study of motifs becomes necessary in understanding what was unsaid through what was said. The medium of writing, like that of caricature and dance, channels these repressions because, after all, the separation of writing and writer, or the alienation of writing from writers makes it easier on the latter to express using indirections. As Santanu Das states in his analysis of war lyric: "between the sensate body and the printed voice, between experience and expression, come language and linguistic form" (77). 
The Aural for the Oral in Irish and Lebanese Dance

A popular Irish joke states that the Protestant Church in Northern Ireland banned sexual relations because they can lead to dance."The Anglo-Saxon tradition viewed the body as shameful and sinful" states Judith Lynne Hanna in her book The Performer-Audience Connection. "Natural acceptance of the body and receptivity to its message appear in rhythm" adds Hanna (48). The inhibition of torso movements in Irish dance and the transfer of expression to rhythmic feet explain how an oppressed culture banned from speaking in its native tongue and from dance, channeled its message of rebellion to feet. This chapter seeks to establish that Irish and Lebanese dances, which are similar in figurations and steps, are forms of expression equivalent to language and used to voice rebellion aurally instead of orally through the heavy use of foot-related dance steps. Additionally, it claims that the decline in the Irish tongue is linked to the rise in dance thus channeling an oral rebellion to an aural one. In the case of Lebanese dance, the less intricate foot work is the result of dances done to sung poetry versus dances done to music alone as is the case in Irish dances. When the message of resistance is expressed orally and aurally simultaneously, foot work in the Lebanese dances become simpler and less dialectic so as to express a dialogue between opposites.

This chapter starts with the explanation of how heavy stomping in dances signifies rebellion and a call for freedom. Steps in different Lebanese and Irish dances thematically related are analyzed and interpreted to highlight how the stomping of feet is directly related to the voicing of an unavowed message of resistance. Exploring the concepts of offense and defense in relation to space and place in dance illustrate the significance of the steps. Additionally, this chapter explores the differences between dances executed to sung poetry versus dances performed to music only in order to assert the claim that the unvoiced message gets declared in dance. Finally, highlighting syncopation in Irish dances might help prove 
how even in dance, displacement proves the presence of a traumatic unsaid which finds indirections in dance in order to shock the spectator thus acting as a defense move.

Within the course of my research, I have not been able to find any studies which correlate the decline of the Irish language with the rise in Irish step dance. However, I strongly posit that the suppression of the Irish language had a direct influence on the rise of modern Irish dance not only because the two occurred within the same century, but also because the message of rebellion is clear in Irish dance especially in its elements of secrecy and rebellion. In order to better explain how this message was transferred from one medium of self expression to another, I shall provide a short historical background to show how a decline in language gave rise to dance.

Historically, it was the Tudors of England who first saw the need to Anglicize Ireland in order to subdue it for once and for all "in tongue, heart, and every other way" as Tudor writer, Sir John Davis recorded in his treatise of 1612. Though The Statute of Kilkenny, which was passed in 1366 by the Anglo-Irish Parliament, decreed heavy penalties against all who practiced the Irish culture, the law was not fully implemented until over 128 years later (Haurin 2). During the Tudor era, the suppression of the Celtic tongue was part of an overall cultural suppression which aimed at wiping out everything Celtic and replacing it with English language and culture. Though a third of the country spoke Irish by the end of the eighteenth century, the upper classes, rich families, and merchants spoke only English. Irish monglots consisted of peasants and the poor who were forced to emigrate during the period of the Great Famine of 1846 thus leaving the country with a small minority of Irish speakers. With the decline of their language and culture, the Irish held on tightly to certain traditions and started exercising them in secret. Dance masters emerged around 1750 and roamed the country to publically teach dance to the youth after Ireland had practiced dance in partial secrecy for over a century (Haurin 2). Parishioners were, of course, against these practices, and constantly sought to suppress them. According to Haurin and Richens, small 
children were placed as watchers on the roof and were asked to tap a certain beat in order to alert dancers below of the approaching parishioners.

Modern Irish dance developed with these dance masters since prior to that the art was highly influenced by the French and English quadrille dances or ballroom dancing. The dances were then regulated by the Gaelic League which was established in 1893 and which attempted to revive the Irish culture. Early Irish dances used soft shoes, and step dancing started emerging in the mid eighteenth century. Dance shoes at that time had wooden soles which gave way, towards the end of the eighteenth century, to more flexible leather shoes with English copper pennies attached to the heels (Hanna 48). The sean-nós dancing in Ireland grew from an indigenous form of dance that developed alongside traditional Irish music, while the céilí [kāli] dance (literaly translated as old style) was invented in the late nineteenth century by the Gaelic League which selected various cultural practices to assert a cultural nationalism (Foley 35).

The preservation of Irish music occurred as a response to the development of nationalist political consciousness and resulted in attributing symbolic emancipation to music (White 1). Though that conservation hindered artistic regeneration of this art in hopes of preserving the traditional, it led to the rise of particular Irish dances which use hard shoes. This coincides with the English suppression of the Celtic language in Ireland, and perhaps may be seen as a displaced response. Nowadays, the largest gathering of sean-nós dancing occurs at "An Oireachtas na Gaeilge," an annual celebration which seeks to resuscitate the Irish language, but which does so through dancing. The existence of the Celtic language is assured, once again, through dance, for its forced suppression is what gave rise to this bodily language in the first place. Additionally, the use of hard shoes implies that there exists a need to voice or vocalize more prominently this new form of language.

Dancing as a form of liberation seems to be considered by dancers a fact rather than an opinion. According to many dancers and dance studies, dancing liberates the body from 
constraints imposed upon it by society and, ultimately, politics. Dancing became an important aspect of anthropological studies in general, and feminist studies in particular. Additionally, dance and power struggle seem to have grabbed the attention of many dance academicians interested in studying the liberating effects of dance on oppressed cultures.

In her introduction to her book "Dance Therapy and Depth Psychology," Joan Chodorow states that "every emotion has a survival value ... But the same emotions, when repressed and denied, can restrict and distort the body" (3). As far as Irish dancing is concerned, contradictions in the body posture of the Irish dancer can be best explained as the body's need to suppress and express. Solid and restrained upper-body posture with arms tucked to the sides contradicts the quick and complicated footwork which mark the Irish jig. Helena Wulff explains the reason behind the adoption of this posture as follows:

It seems likely that the English view of the Irish as 'ruly', which was still prevalent in the late nineteenth and early twentieth centuries, had an impact on how Irish competitive dancing styles and regulations evolved in tandem with ideas of national identity and morality. This especially concerned the characteristic stiff upper body and straight arms, which are accentuated by the contrast with the speedy and intricate footwork in competitive Irish dancing. . . Some older people I have interviewed in the dancing community were quite explicit about the fact that the stiff posture came about from the beginning as a way to train the Irish in manners. It was considered good for the Irish character to keep an erect posture (Wulff, in preparation). This echoes Foucault's (1979) famous argument about how the power of discipline moulds docile, political bodies that display more ability but in fact are controlled. (182)

Had it not been for the English and their view of the Irish, best portrayed in British literature, the Irish would not have felt the need to adopt "English" manners in dance. This is clearly portrayed by the following example; Jane Austen, an English novelist, advised her niece, who was working on a novel of her own, not to write about Ireland given the difference in manners. She commented on the behavior of a gentleman, after a ball in 1804, and said that he must have been Irish for he had contravened proper mannerisms in dance and courtesy (Ross 12).

Whether the stiff upper body posture was to reflect Irish manners or not, the direct evidence of suppression lies within this posture. Moreover, I have noticed in Ireland the 
presence of half a meter stone walls dating back to medieval times. People, as I have heard from the elders in Irish countryside, used to stand behind these walls as the Red Coats marched down the streets. Since dancing was banned, the Irish danced in their places while keeping a stiff upper body. It got to a point where dances were evaluated based on the space the dancer utilized while dancing. Highly skilled dancers could execute their footwork in a space not larger than a dinner plate (Miner 2), and jigs were executed in moves close to the ground, unlike the reel which included leaps and jumps and which originated in Scotland around 1750 (Haurin and Richens 7).

In her article "Feet, Fate, and Finitude," Nikolopoulou explains that the erect posture of homo sapiens marks the beginning of civilization and thus finitude as Freud claims, for the standing human is a linguistic being who suppressed the sense of smell and replaced it with the sense of vision (176-178). She states:

This is what Bernd Jager also means when he writes that for Freud the moment of standing up "does not simply occur but . . is instead assumed or inhabited" $(1988,8)$. It does not occur as a biological fact; rather in its happening, the human being itself happens for the first time. Jager continues: "This standing up is all at the same time a wounding separation and emergence into humanity. ... Whatever may have guided life up to this decisive point remains obscure. But beyond this point human life would be desire in the form of a standing up and in the form of a falling back into oblivion" (8). Standing up is an emergence, a coming-to-be human, while the wound of separation refers to the severance from the undifferentiated natural state from which primordial humanity emerged. This state, Jager contends, cannot be accessed, and it is precisely its irretrievability that becomes a wound for the nascent human being. In turn, this wound, which exceeds expression and articulation, paradoxically also demands them. The need to articulate this wound marks in fact the entrance into meaning. Consequently, standing up as the loss of primordial unity is inextricably related to meaning and to language. (177-178)

When articulation is suppressed, the human body expresses itself in other forms - namely body language and dance. Feet, on which civilization stands (metaphorically), assert a presence through movement, but when movement is suppressed, stomping becomes an alternate expresser of anger and the articulator of rebellion ${ }^{2}$. The oral message is channeled

\footnotetext{
${ }^{2}$ Hoofing and tap dancing are used interchangeably in dance studies, but in this thesis I use hoofing to refer to a step that ranges in strength between a stomp and a tap.
} 
aurally, and stomping thus voices rebellion since it can reach the ears like spoken words can. The limitation of language and body through oppression lead the feet, which are the least visible in the Irish setting as highlighted above, to express rebellion and a call for freedom. Exactly like an angry child stomps his feet in defiance, adults express rebellion through the stomping of feet in both Irish Céili and Lebanese Dabké-the more socially acceptable forms of defiance.

The Irish and Lebanese dances which will be analyzed in this chapter both come from theatrical performances thematically related to the history of oppression in both Ireland and Lebanon. They contain elements of the folkloric dance of both Ireland and Lebanon. Michael Flatley's Celtic Tiger $^{3}$ includes an act about the history of Ireland from the Neolithic ages up until the liberation of Ireland from the British rule, and the Lebanese musical by Mansour alRahbani titled Saif 840 or the Summer of 1840 talks about the Lebanese rebellion against the Ottoman rule.

In "Celtic Tiger," the show starts with the words "there is no place like home," thus alluding to the Irish Diaspora. Then the dancing begins in the dark with the dancers stomping, hoofing, and tapping in complete darkness thus emphasizing the form of secret expression which Celtic culture which was forced to endure for over a century. The staging of the Irish history in Act I of the show traces the struggles of the Irish people to the offenses committed by the Red Coats against the Irish in the early $19^{\text {th }}$ century, even though the English rule over Ireland had started centuries earlier ${ }^{4}$.

Another dance titled "A Call to Arms" is one of particular interest to my search and is similar to a dance performed in Saif 840 which is also a call for rebellion titled “ لمعت ابو اق

\footnotetext{
${ }^{3}$ Michael Flatley's dance performance "Celtic Tiger"s performed in Budapest in a massive opening night in front of 100,000 people, making "Celtic Tiger" the biggest dance performance in history. It presents the history of Ireland in two acts (26 scenes) of dance and music.

${ }^{4}$ The Anglo-Normans first arrived in Ireland in 1169; England's king was Henry II.
} 
"الثورة (The trumpets of rebellion gleamed). "A Call to Arms" begins with a black background and a voice which declares: "Irish men and Irish women: in the name of God and the dead generations from which she receives her old tradition of nationhood, Ireland, through us, summons her children to her flag, and strikes for her freedom." The dance then starts with one dancer hoofing in front of the lined up Red Coats. He taps fast and hard using mostly his soles and toes, and rarely the heels because the heel creates a stronger sound and it is more of an affirmation of presence. The stage then goes dark, and lightening strikes in the background and the Irish dancer starts drumming and Irish music starts playing. The Red Coats appear baffled and confused as Irish men appear in one unified line on stage, having emerged from behind. A picture of the post office in Dublin appears in the background alluding to the Easter Rising which marked the first rebellious activity of the $19^{\text {th }}$ century against the English. The Irish dancers form a circle in the middle and start tapping, while the Red Coats surround them stand still. The dancers in the circle represent rebellion and then engage the Red Coats in a battle-like dance by forming lines facing each other and intensifying the tapping of their feet. The circle in the middle symbolizes self defense and containment, while the straight lines symbolize offense and rebellion lined up in the face of the enemy. The stomping increases and is accompanied by leaps and jumps which symbolize springing on an enemy, and then the dancers start shouting "Hey! Hey!" with each forward jump before all dancers collapse on the floor marking the end of the dance. Most of the steps involve four, six, or eight soft taps followed by one strong stomp. The rhythm produced by these steps resembles the sound produced by a Durbek - a Middle Eastern percussion instrument. With respect to this dance, linguistic expression is transferred to the feet in hopes of conveying a message of resistance.

The play Saif 840 talks about the rebellion of the Lebanese commoners against the Turkish rule which was aided by the Lebanese warlords. The folkloric dances in this Rahbani production contain steps from traditional dances performed at cultural events. One particular 
dance about rebellion follows the lyrics of a song performed by Ghassan Saliba titled "The Trumpets of Rebellion Gleamed." The song goes as follows:

$$
\begin{aligned}
& \text { لَكَعِت أبو اق الثَورة } \\
& \text { سكن الحقد المسافات الصات } \\
& \text { و والاعلام الدمويِّة، }
\end{aligned}
$$

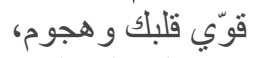

$$
\begin{aligned}
& \text { با بتوصل على الموت، } \\
& \text { با بتوصل عالحريّة! } \\
& \text { يا ارض الفقا لفر ا ياوطني. } \\
& \text { يا هَم الشُعر ا باوطني. } \\
& \text { هالحزن اللي صار الشعار } \\
& \text { ما عمرو صنار ، لمئار } \\
& \text { يحكمنا غرباء وتجّار ! } \\
& \text { بندهلا با وطني وحبياء وتجار! } \\
& \text { يابحر المشارق الرحيلّه } \\
& \text { لا بدِّي تكون الطغيان }
\end{aligned}
$$

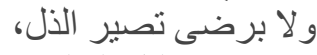

$$
\begin{aligned}
& \text { وبوقف بليل العالم } \\
& \text { نشحَّ الاستقلال بالعال } \\
& \text { عابو اب الأمم الغريبة. }
\end{aligned}
$$

The trumpets of rebellion gleamed

Hate resided in the distances

And the bloody flags.

Strengthen you heart and attack

You'll either reach death

Or you'll reach freedom.

My nation, the land of the poor.

My nation, the burden of poets.

This melancholy which took place

Never took place before;

We're ruled by strangers and merchants.

I call to you my beloved nation,

The sea of the vast orients

I don't want you to be a dictatorship

And I won't accept you being broken,

And stand at night and beg for independence

At the doors of foreign countries.

The lyrics, written by Mansour Rahbani, convey the rebellious message of the dance in detail.

The dancers stomp their feet to the semi-quick rhythm and dance with clenched fists raised above their heads. The steps are not varied and complicated, but reveal a call for freedom and compliment the words of the song. The Lebanese dancers convey anger at the oppressive 
state they have been living in for centuries, and their dances done to lyrical song sufficiently portray their feelings of rebelliousness ${ }^{5}$.

The concepts of space and place in the dances of the Irish and Lebanese dances have a significance which extends beyond the notion of stage and area. As previously noted, Irish dancers around the time of the Dance Masters took pride in being able to execute their complicated footwork in a limited space no bigger than a dinner plate. However, with the establishment of the Gaelic League, judges urged dancers to utilize stage space and deducted points for lack of stage use (Haurin 4).

To stomp and tap in one place can be considered as an act of defense ${ }^{6}$. To stomp is to make oneself heard without even uttering a word, and to tap, as shown in the Irish dance discussed above, is to show defiance. However, the movement is limited to one place with oppression having a grip on the performer. When the Irish were not allowed to dance, they performed behind walls while restraining their upper torsos in order to give the impression of being immobile. Their hoofing was to substitute oral defiance. In her article "Hoofing to Freedom with Soul and Sole," Judith Lynne Hanna argues that dances such as Tap which has its roots in Irish dancing, is a performance of power in many instances: it renders the performer in control of his body, it teaches him discipline and self-control, and it helps the performer gain freedom to use his body as he pleases (51).

On the other hand, utilizing space while tapping can be viewed as an act of rebellion or offense. In Michael Flatley's "Easter Rising," the dance of the Irish against the Red Coats starts in one place by one dancer and then slowly expands to include numerous dancers who utilize the entire stage space. At one point, the dancers not only mirror the offensive dance

\footnotetext{
${ }^{5}$ The Lebanese historian Amin el Beani mentions in his book Fusul min al-'Adat wal Taqalid fi Lubnan that the traditional dance Assaif wal Turs alludes to the initiation of a battle between two armies.

${ }^{6}$ New Zealand's “All Black's" Rugby team starts every game with a war dance called "The Haka," adopted from the indigenous people of New Zealand the Māori, in which the players stomp and make throat slicing movements to the sound of their rhythmic feet in order to offend and scare their opponent.
} 
moves of the Red Coats, but also add more taps to the moves to signal offense and not merely defense. Steps evolve from being mere bars of eight to ten sole and heel taps to include jumps and leaps which are normally found in soft-shoe dances. Towards the end of the dance, dancers start yelling out "Hey! Hey!" while leaping and kicking. Additionally, the scattered dancers line up to resemble organized lines of soldiers united against a common enemy in face of the already organized line of Red Coats and engage in a battle of loud stomping and hoofing before collapsing on the floor thus ending the dance which represents the historical confrontation that took place in Dublin in 1916 between the Irish rebels and the Red Coats. The "aural" space of a dance performance, namely the stage, becomes the acoustic substitute of voice. "Objects and spaces could depict strong emotion and intense symbolism precisely when they [are] no longer constrained by having to replicate physical attributes" state Blasser and Salter in "Spaces Speak, Are you Listening?" (163). Utilizing hard shoes in creating a rebellious atmosphere is coupled with the utilization of space as a claim of territory. At one point in history, both the Irish and the Lebanese had to advance against the enemy in order to liberate their land. This act of liberation started, metaphorically, with one step taken forward by them, and a step taken backward by their enemy.

If the aural aspect of the Irish and Lebanese dances is associated with space since sound is encompassing and engulfing, then the visual aspect of these dances can be best associated with place and stage. Lining up a fort wall of dancers against the enemy and maintaining one's grounds marks their defensive act. To see one firmly holding one's ground is to realize that one is deeply rooted in one's place. The lining up of dancers in a straight line in both Irish and Lebanese dances contrasts with the mobility and fluidity of both French and English quadrille dances. Even the names of certain Irish dances, "Walls of Limerick" and "Waves of Tory," in which dancers line up for dancing can mean resistance and defiance.

Auditory and visual spaces in cultural dances substitute for language when expression ceases being oral, and extend beyond the visual resistance to include an auditory offense to 
the senses because stomping and hoofing create aural effects aimed at scaring away an invader. "Auditory spatial awareness includes all parts of aural experience: sensation (detection), perception (recognition), and affect (meaningfulness)" (Blesser 14). As a result, the spaces and places utilized by the dances of the oppressed mark resistance as well as rebellion. Therefore, space occupied by voice (through song) or sound (through audible dance steps) enhances the rootedness to place, by dancers trying to assert a presence and shows a connection of oneness with the land.

From observation alone, I have noticed that most Lebanese dances done to sung poetry are less rigorous than the dances done to music alone without lyrics. As if the words substitute for steps, dances done to sung poetry contain less syncopation and expressive steps. Similarly, the Irish dances done to music without lyrics involve heavier stomping and hoofing. I find the intricate footwork in the Irish dancing to be a mere substitution for the absence of the sung word which can be laden with implications of rebellion and proof of presence. In his book Homo Narrans, John D. Niles explains the power behind the sung word in oral literature as follows:

[...] wordpower finds expression not through the writings of individuals longing to fill a separate space, but rather through people giving voice to "unison songs" that rely on a fund particularly associated with the ancestors who voiced these things before we did ... The knowledge that finds expression in traditional songs and stories helps literally to bring the members of a society together through the quasiritual occasions of performance. At the same time, it reinforces a people's sense of identity and self-worth by preserving social memory through engagement with ancestral past. (195)

What the Irish lack in expression through song and poem because of the suppression of their language by their oppressor, they make up for with their step dancing. On the other hand, the singing, clapping, and yelling that the Lebanese include in their dances substitute for expression in dance steps. The Lebanese did not face a suppression of language, and therefore could express in song and poetry their rebelliousness. This, in my opinion, led to the subordination of dance to sung poetry. This is clearly illustrated in traditional Lebanese dances which rarely start without a preceding Mawwal, or a poetic prelude. 
"تيضل الصوت يوَدي" Voice is presence. The slogan of the Lebanese newspaper annahar (so that the voice continues to reach) stands for the long history of Lebanese freedom of expression. Though there is no voice in writing, the free word substitutes the voice of presence. Additionally, to be able to "voice concerns" also reflects the importance of voice in reporting injustice. In short, voicing rebellion in song can substitute for other bodily expressions such as dance or even physical violence. Voice also brings together people who speak the same language through oral communication. In his book Oral Poetry: An Introduction, Paul Zumthor states: "Between animal and human societies, only the latter hear their own voice as an object emerging out of the multiplicity of noises: around this voice the social bond is strengthened and solidified; meanwhile poetry takes form" (5).

The poems in Lebanese dances convey more power than the lack of song in Irish dancing. Though the Irish do yell and shout in a few of their dances, this, according to Zumthor, is impotent:

But a voice without language (a shout, voice-control exercises) is not distinct enough to convey the complexity of the forces of desire animating it. The same impotence affects language without voice, that is, writing. Thus, our voices demand language and at the same time enjoy an almost perfect freedom of use vis-à-vis language. It culminates in song. (4)

Both song and dance compliment each other. However, the expressive ability of sung poetry, in my opinion, undermines the value of the dance or the emphasis placed upon it by the performer. "Language without voice is unthinkable" states Zumthor (6), and when the sole communicative language is dance, dance steps become more complicated, complex, and heavily laden with meaning.

In their article, Writing Rhythm: Movement as Method, Cancienne and Snowber state that "Combining dance, a kinesthetic form, and writing, a cognitive form, can forge relationships between body and mind, cognitive and affective knowing, and the intellect with physical vigor" (2). In other words, dance and poetry combined can better express this rebellious message. The end result, in Saif 840 , is a staged rebellious act against seven 
hundred years of Turkish rule under which Lebanon suffered from poverty, famine, and lack of freedom.

Syncopation, a musical term, means the modification of rhythm which occurs when a weak beat is stressed. Dance borrows this term to mean the displacement of beats and rhythm in taps. Displacement here means the substitution of stronger beats with weaker ones so as to highlight the latter. Strong beats are rendered weak while weak beats are rendered strong so as to shock the spectator and throw him off guard.

Beat and rhythm are elements of nature such as the galloping of horses and the beats of a heart. When the spectator knows what to expect next because the dancer is following a specific dance pattern, the dance becomes monotonous. In the case of Lebanese dances, the spectator watches the dances and listens to the lyrics of the song in order to help interpret the dance. On the other hand, the spectator of the Irish dances cannot guess the move that will come next because of the syncopation of beats which the dancer improvises. This improvisation shocks the spectator and keeps him on his feet (metaphorically), alert to the jolting effect of the dance. Interestingly, this form of displacement done by the dancer gives him the power to manipulate the spectator and retain the power. This syncopation and displacement of steps occurs commonly in Irish dances. The absence of words to accompany the dance creates a need to voice what has been suppressed. Whether consciously or unconsciously, the displacement of beats allows the dancer to bring to the surface what cannot be sounded. In order not to seem affront, the dancer syncopates in a dialectic manner with the spectator, and plays the game of shock and offense through rhythm.

Though the historical and social contexts of Lebanese dance differ greatly from those of Irish dance, they share remarkably similar steps, and their rhythmical feet are like the metrical feet of a poem. The Irish prefer the five tap wing which is similar in its stress and unstress to the iambic pentameter commonly followed in the metrical poetry of the AngloIrish poets. The Lebanese, on the other hand, follow the music while dancing and rarely 
divert off the accents of the song being danced to. With the exception of the leader of the Dabké who presides over the dance and diverts off the dance routine with a display of jumps and intricate hoofing, the dancers follow the rhythmic pattern of dance.

The term "metrical foot," derived from the tapping of the foot, is a rhythmic pattern which can be quantitative or accentual. The adherence to the metrical foot in Irish poetry could imply solidity in the expressive voice which may have resulted from repressed language and the accentual quality of the beat in Lebanese poetry (since many scholars agree that Lebanese Zajal does not follow a meter) may be the result of no language suppression. The "foot" remains a main tool of expression in dance; however, it has been transferred to poetry to become a motif which substitutes voice.

Carl Jung wrote a paper in 1916 in which he discussed how dance and body movement give form to the unconscious (Jung 67). Not until half a century later was serious attention paid to the therapeutic importance of dance from which a whole school of dance studies sprung. Cultures have, for centuries, understood the power of dance in liberating the body and soul. This liberation occurs, as Jung has suggested, because dance helps the unconscious manifest itself in what is socially and politically acceptable.

In oppressed cultures such as the Irish and the Lebanese, dance has taken a different form which involves hoofing and the stomping of feet. The rhythmical similarity of the two dances is astounding. Whether to express resistance or rebellion, the message gets transferred through the heavy use of feet which, following the claim I discuss throughout my thesis, is a motif indicating displaced emotions suppressed because of political oppression. It is one of two motifs which represent voice - the other one being eyes and is discussed in the other two chapters.

Unlike in the case of caricature discussed in chapter three, voice and noise supersede vision. Zumthor writes:

The dense backdrop of potential and interactive meanings distinguishes voice from sight, another bodily emanation associated with voice in myth as well as in 
performance. Whatever may be the expressive and symbolic power of sight, it lacks the concrete solidity of voice, of tactile sensation and urgency of breath. Unlike speech, it is unable to use a simultaneously absent and present object to reset games of desire, constantly to recast the game of desire in an object that is at once both absent and present in the sound of words. (6)

The message of resistance, suppressed with the suppression of language, finds its way out through dance. The oral gets channeled aurally, and the displaced emotions find a way out through hoofing. Hoofing becomes a call for freedom.

Why do we dance? Scholars have approached this question from many a perspective be it anthropological, social, cultural, psychological, or physiological. All agree that dance is a form of expression whether it has an ultimate spiritual goal, or simply for the purpose of entertaining oneself. However, cultural expression in the form of a unified dance has its roots in both the psyche of the individual and overall cultural consciousness. As previously mentioned, Jung considered dance as having its roots in the human unconsciousness and is a manifestation of what is hidden there. Nevertheless, the need to express the anguishes and agony of an oppressed culture leads the individual to articulate what has been suppressed. When the verbalization is suppressed, it finds indirections and thus expresses using another form of expression, that of dance. However, stomping and hoofing in dance are direct expressions of resistance and rebellion. They affirm the direct link to the land in which the individual is deeply rooted as in the case of the Irish and Lebanese. Dialectical expression through the alternation between taps and heels, jumps and stomps, strides and turns, as well as syncopation and stressed beats all express the offensive and defensive moves that oppressed cultures utilize in dance in order to express resistance and rebellion. In the end, to dance is to move, and to move is to prove existence. 
Eyes and Feet Motifs in Irish and Lebanese Political Caricature

"Caricature narrow[s] the gap between art and life" states Judith Wechsler and

Baudelaire claims "caricatures are often the most faithful mirror of life" (Wechsler 317). The ability of caricature to reach and influence vast numbers of people has scared many politicians throughout history. William Marcy Tweed, New York City's Democratic leader known as "Boss Tweed," was quoted by William Murrell saying "I don't care what they print about me, most of my constituents can't read anyway_but them damn pictures!'” (Wechsler 46).

Caricature and cartoons are used synonymously by academics. Caricature finds its root in Italian "caricare" which means "to overload." It has come to mean that the features of the person caricatured are distinctly exaggerated to produce a comically grotesque effect. However, the aim of caricature often goes beyond mere exaggeration to interpretation of the object. Therefore, the caricaturist's gaze reads and represents the inward characteristics of objects, which are, most of the time, people in power. Cartoons, on the other hand, represent the intercourse between caricatures, as Martha Banta explains in Barbaric Intercourse. She adds that "cartoons consist of caricatures inserted into socially layered relationships" (4). In short, caricature is the exaggerated drawing of a person, while cartoons are the series of pictures which tell a story and do not necessarily distort the image of what they represent. In this chapter, both terms are used interchangeably because many of the caricatures used are part of a cartoon.

This chapter seeks to establish that the motifs of eyes and feet in Irish and Lebanese caricatures serve the same purpose: to voice the opposition against the abuse of power, and that these motifs surface unconsciously as a result of political suppression and trauma, yet interdependently serve a message of resistance.

To verify the message of rebellion, this chapter will discuss the social, psychological, and political implications of these caricatures to illustrate how the motifs of eyes and feet, 
which appear in resistance caricature, are a result of social and psychological repression directly resulting from political oppression. Additionally, the chapter suggests that these drawings, considered a visual medium of expression, serve their message of both resistance and rebellion exactly like dances do in the Irish and Lebanese cultures.

The chapter consists of three parts; the first part deals with the drawings of Naji elAli, a Palestinian who lived in Lebanon and represented the Lebanese ordeal with Israel for most of his life. Cartoons of Naji el-Ali in specific are heavily laden with eyes and feet motifs; therefore, deriving quotations from Naji el-Ali's diary helps better explain why he might have associated eyes and feet with oppression and rebellion. The second part presents Irish caricatures from different time periods to establish again that these motifs of eyes and feet are not time bound but surface as a result of oppression regardless of time and place. Finally, the third part presents literature reviews on political caricatures and explains the significance of resistance caricature in molding public opinion and serving a message of rebellion.

Theorists often discuss the cartoonist's gaze as if it is the judging eye of the entire society. The eyes of the cartoonist are fixed upon an event and present in a drawing what the eye perceives as a reality. Martha Banta poetically compares the eyes of a cartoonist to the eyes of God. She states: "This is a world in which the God of Christian cultures has vanished, but the 'omniscient eyes"' that keep the body—-the soul's envelope — under surveillance are still there, replaced by ... the cartoonist's gaze (53).

The gaze of the cartoonist translates the struggles to drawings or pictorial statements. Interestingly, because the political upheavals persist in Lebanon and Ireland, the cartoons still have an effect on the onlooker and can be understood in today's political context. They cross boundaries of time. Additionally, they have acquired a transnational meaning to all who have faced a similar enemy. What stand out in these cartoons are the motifs of eyes and feet which 
strike the onlooker as meaningful statements representing oppression, pain, and absence of voice.

The Definitive Book of Body Language by Allan and Barbara Pease heavily emphasizes posture. Physical posture or stance tells plenty about the feelings of a person. When a person gets reprimanded or feels humiliated, she tends to drop her head and look down at her feet in a submissive manner. In contrast, children show defiance by stomping their feet especially when, for example, they throw temper tantrums. As we get older, we learn how to control these bodily movements or expressions and channel them through socially acceptable forms of defiance such as linguistic defiance. Mental imagery arises primarily from sensations of bodily movement and position rather than from visual or auditory sensations. Motility shapes some of the motifs present in el-Ali's cartoons. However, the bodily posture of humiliation makes one associate feet with the feelings triggered by the aggressor, for the inability to speak or voice defiance renders the person fixated on the body part which he can voice defiance with and which falls right under his sight: his feet. Voiceless becomes shoeless and, in extreme cases, feetless ${ }^{7}$.

This repression of voice isn't present from the very beginning and cannot be generally identified with motifs of feet. Freud explains:

Repression is not a defense mechanism present from the very beginning. . . . it cannot occur until a sharp distinction has been established between what is conscious and what is unconscious: . . . the essence of repression lies simply in the function of rejecting and keeping something out of consciousness. (286)

We cannot claim that caricaturists consciously depict submission through the use of foot motifs and catharsis through the use of eye motifs. However, we can, with the help of Freud's theory, establish that these motifs express what is rejected out of consciousness as a result of

\footnotetext{
7 Around 1998, a petition was circulated on the internet calling for action by the government of the United States of America to stop the atrocities committed by the Taliban against women in Afghanistan. The petition lists bans imposed upon women and includes a ban on wearing high heel shoes "which would produce sound while walking." It adds that "man must not hear a woman's footsteps." Women, the petition states, were forced to paint the windows of their houses so that they cannot be seen. Women were banned from being both seen through windows and heard through footsteps which insure presence.
} 
trauma. When an eye-witness experiences trauma, he receives and retains these experiences, but consciously tries to deposit them in the subconscious. This leads to the development of anxiety. A coping mechanism would be to form a cathexis coiled around this rejected idea in hopes of lessening its damaging effect over the individual by attaching itself into the substitute or displaced idea. This "substitute representation" as Michael G. Levine explains, plays a part then acts as if it were that part "thus apparently wavering between mere appearance and actual existence." He adds: "In terms of location, the substitute seems to straddle (and thereby to mark) the limit between the repressing and the repressed" (85).

Images are registered through the senses: motile, visual, and aural. Because the brain quickly seeks displacement as a defense mechanism to protect the individual from the experience of shock, these images form cathexes to the senses which registered them in the first place in hopes of keeping them at this level and preventing them from being registered in the consciousness. As a result, they get thrown in the unconsciousness with their cathexes and then resurface in art in the form of simplified motifs. The traumatic experiences of the cartoonist Naji el-Ali led him to express struggle and the need for rebellion and catharsis through the motifs of feet and eyes respectively. Cartoons often present rich psychological insight especially when evaluated for their traumatic content. Art production, as psychoanalysis claims, can be an overflow of a repressed unconscious mental activity. The artist represents actions that are habitually repressed from consciousness.

Sights, smells, and sounds associated with oppression are internalized then kept away from the consciousness because of their traumatizing effects. However, the artist depicts these indices of trauma in the form of art. Art, therefore, sublimates trauma and helps the reader or onlooker to rediscover himself through an interaction with the text (Schwartz 214). The cartoonist does not structure reality in relation to his wishes and aspirations, but rather paints a representative picture of the traumas affecting him, and aims to condense in one 
picture the struggles of his people. Others facing the same situation then read these cartoons and better deal with their hardships when they see them represented in drawings.

Naji el-Ali was born in 1938 in the Palestinian village of al-Shajarah (the tree) claimed to be home of the tree which Jesus Christ used to rest under, and which was erased off the map by Israeli forces. After the Palestinian exodus in 1948, he moved with his family to the Palestinian camp Ain el-Helwi in Lebanon, and his career began with drawing on camp walls until he was finally noticed by Ghassan Kanafani, a renowned Palestinian novelist and journalist, in the late 1950s. Kanafani encouraged el-Ali to publish his first cartoons in alHurriya magazine. Naji el-Ali later moved to Kuwait to cartoon for al-Tali'ah magazine after dropping out of the Art Academy in Sidon, Lebanon, for financial reasons. Though his drawings condemned the Israeli Army in particular, Naji el-Ali had many enemies in and outside the Arab world:

Not a member of any political party, [Naji el-Ali] strove to speak to and for ordinary Arab people. His life was seamlessly interwoven with the trails of exiled Palestinians. Due to invasion, censorship and threats, he lived in exile most of his life. [He] was an uncompromising critic of a regressive Arab political culture and western intervention in Arab affairs. (Asfour 1)

His subtle satirical cartoons mirrored the experiences of refugee Palestinians and Lebanese people who endured the aggression of the Israeli invasion of Lebanon in 1982. His genius is perhaps best encapsulated in his own description of Hanzalah, the little spectator who appears in most of his cartoons:

This child, as you can see, is neither beautiful, spoilt, nor even well-fed. He is barefoot like many children in refugee camps. He is actually ugly and no woman would wish to have a child like him. However, those who came to know 'Hanzalah,' as I discovered, later adopted him because he is affectionate, honest, outspoken, and a bum. He is an icon that stands to keep me from slipping. And his hands behind his back are a symbol of rejection of all the present negative tides in our region." (qtd. in Asfour 2)

Naji el-Ali created Hanzala to remind himself of where he had come from and of his cause. He states: "I was scared that I was slipping into the luxury of life, forgetting my real cause, so 
I decided to create a character that would represent the honest Palestinian who will always be on people's minds" (Khader 2).

Many who wrote articles published on the website dedicated to el-Ali's work speak of how he referred to the period he had spent in Beirut as being the most inspirational. He was forced to leave Kuwait because the government was getting attacked by numerous Arab leaders for not being able to silence Naji el-Ali whose delineative drawings spared no one. He came back to Beirut in 1974 and worked his best years at as-Safir newspaper. His unrelenting cartoons about the strife of the Lebanese and Middle Eastern Arabs at the hand of the Israelis as a result of the establishment of a Jewish state display no national identity of any sort but rather speak about the oppression of despotic states. He was an eye witness to the Sabra and Shatila massacres in 1982 during the Israeli invasion of Lebanon, and his ethical rebellion propped his work:

During the 30 years since I started drawing, I feel I have been through every Arab prison and I ask myself: What is to come after all this? I was prepared to die defending just one drawing, because every drawing is like a drop of water which makes its way through the minds of people. (qtd. in Asfour)

On July $22^{\text {nd }} 1987$, Naji el-Ali was shot in southwest London close to the offices of the Kuwaiti newspaper al-Qabas. After spending a few weeks in a coma, he passed away. During a speech given in 1975 in Kuwait, Yasser Arafat asked: “ من هو هذا ناجي العلي، قولو له ان لم "Who is this Naji el-Ali? Tell him that if he does not stop drawing, I will melt his fingers in acid.”). Naji el-Ali replied “ ان فقدت اصابع يدي سأرسم بأصابع رجلي" (“If I lose my fingers I will draw with my toes”) (Ghanem Ghabash, 1987) Eye motifs are a crucial element of el-Ali's cartoons. Eyes without pupils, teary eyes, flag eyes, fish-shaped eyes, prison-bar eyes, and even barbwire eyes materialize in many of

\footnotetext{
${ }^{8}$ One of his friends reported that he was receiving threats from the Palestinian Liberation Organization in Tunis because a few weeks before the shooting incident he had published a cartoon ridiculing a female friend of the PLO leader Yasser Arafat (El-Fassed, 2004).
} 
his cartoons. These eyes represent the struggles seen by el-Ali in the Lebanese struggle against the Israeli invasion of which he was an "eye" witness. Naji el-Ali frequently referred to eyes and feet as first impressions associated with the memory of his forced banishment with the Palestinians and the situation of his people upon their arrival in the Ain el-Helwi camp. He states:

$$
\begin{aligned}
& \text { اخرجوني من هناك ـ . . إلى مخيم عين الحلوة في لبنان . . . أذكر هذه السنوات العشر أكثر مدًا اذكر }
\end{aligned}
$$

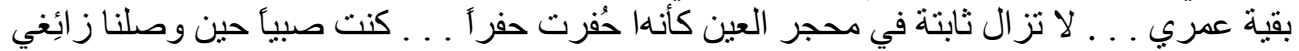

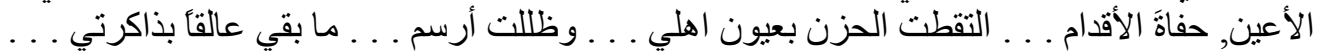

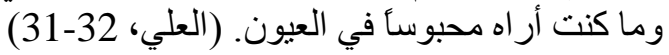

They took me out of there ... to the Ain el-Helwi camp in Lebanon . . . I remember those ten years more than I remember the rest of my life ... They are still stuck in the eye sockets as if they were carved there ... I was a little boy when we arrived with dazed eyes and bare feet . . . I captured the sadness in my parents' eyes . . . and I continued to draw ... what stayed stuck in my memory . . . and what I saw confined in the eyes.

Naji el-Ali wasn't fond of violent protests, but opted to express through drawings instead. He tried joining the Arab Nationalist Party in 1951 but did not find himself capable of fitting in. He could not agree with any of the movements at the time, and opted to work on his own expressing the struggles of his people through drawings. Playwriting attracted him, but journalism was his only option at the time. He states:

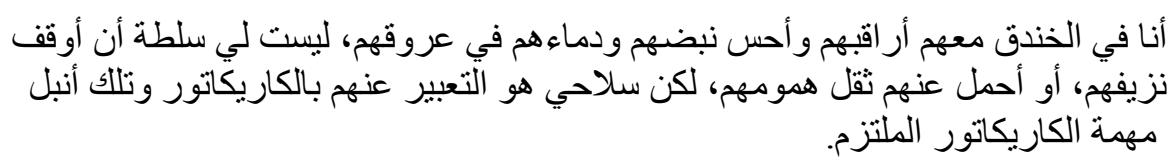

I am in the trenches with them watching them and feeling their pulse and their blood in their veins, having no power to stop their bleeding or to carry the burden off their shoulders, but my tool of expression is caricature and this is the noblest mission of the committed caricaturist. (Limbashiri 5)

His mission was to tell about the struggles of people through drawings. Interestingly, he started adding captions to his drawings when Beirut was under siege to better express his frustration with the situation, and he received criticism from those claiming that he should stick to drawing and not writing. Nevertheless, the captions contributed to the message conveyed in pictures. 


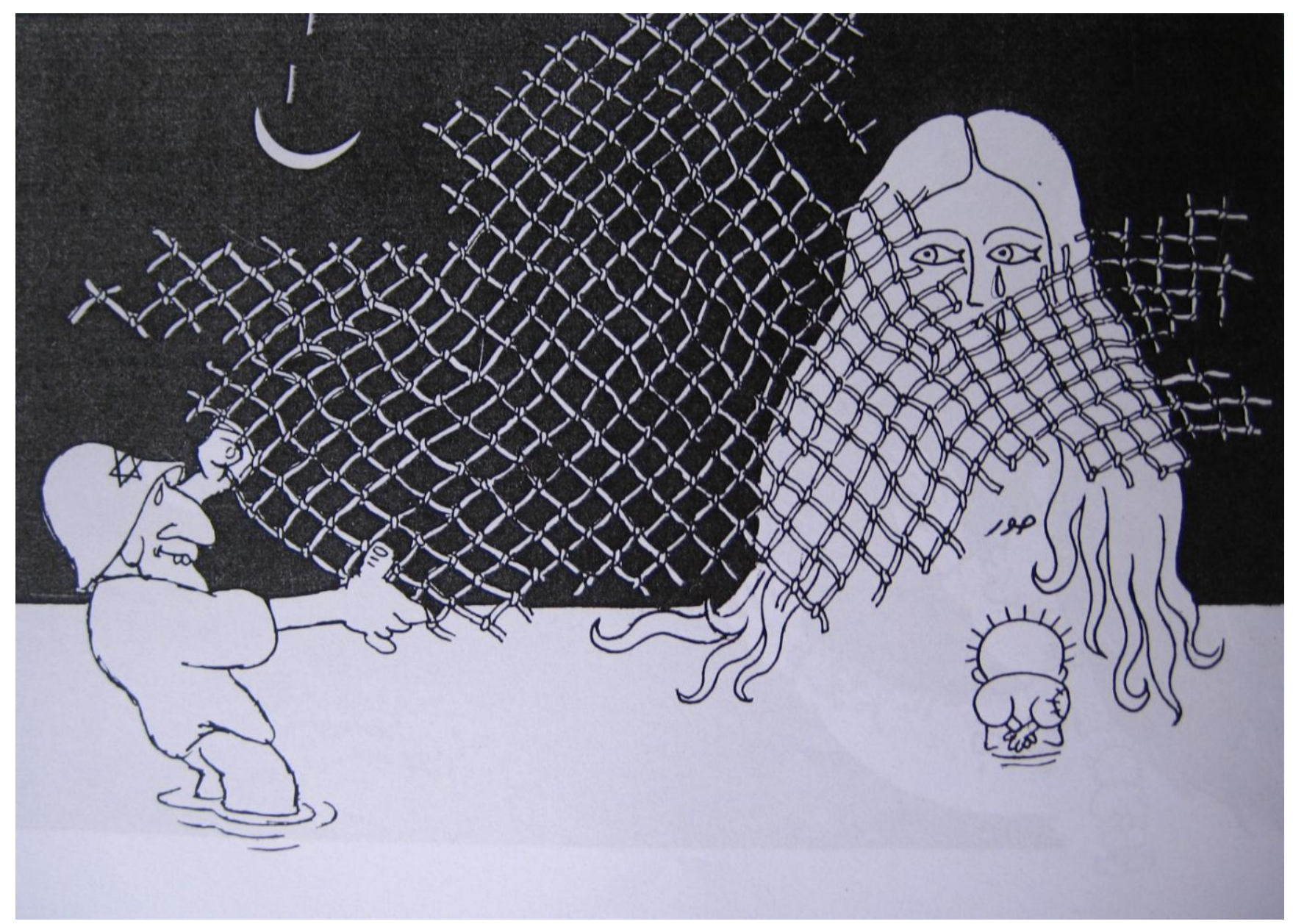

Figure 1

Lebanese cities often appear in el-Ali's cartoons as helpless women being trapped under Israeli occupation. Figure 1 represents Tyre, a coastal Lebanese city, trapped in the fishing net of an Israeli soldier. The usage of Ichthus eyes represents Christians struggling against Israelis in hopes of reinvigorating a cultural memory of Jesus suffering at the hands of the Jews, and these eyes look directly at the soldier who wears a wicked yet triumphant smile. The presence of the crescent indicates that this act was carried out in a dimly lit night in reference to the Lebanese saying "بليلة ما فيها ضو قمر" ("in a night without moonlight”) to indicate that the act of besiege was cunningly carried out at night to evade witnesses, except for Hanzala - the permanent eye-witness. Tyre, a woman, was shamelessly assaulted by an Israeli soldier at night. The fishnet which resembles a galvanized fencing wire is a modern border-setting divider which places cities under siege. Though the city is depicted as a crying woman without arms and legs, she appears larger in size than the soldier and appears 
resistant. Nevertheless, both her eyes and Hanzala remain untouched by the net and seem to be emerging from the water (in contrast with the Israeli soldier who appears to be sinking) thus depicting moral resistance.

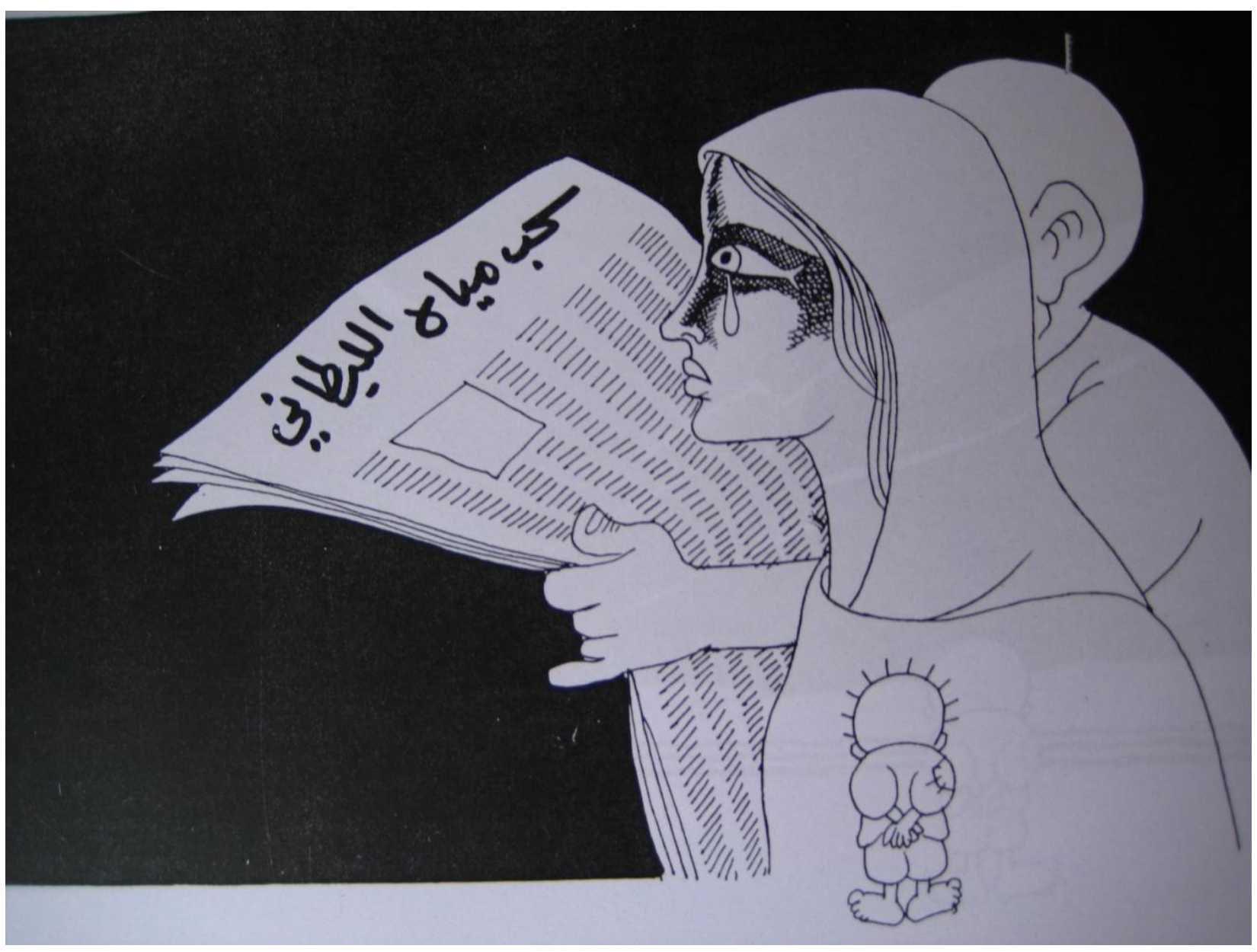

Figure 2

Figure 2 again presents the picture of a woman with Ichthus eyes crying over a newspaper headline which states that the water of al-Litani River is being stolen. Even till this day, Israeli soldiers are being reported by locals to be stealing water from Lebanese rivers since Lebanon has a wealth of water unmatched by its neighboring countries which suffer from frequent droughts.

Although el-Ali was a Palestinian refugee, most of his cartoons depict the struggles in Lebanon, a country which he often portrays as a woman. He sometimes uses the Ichthus, the Greek name for the Christian symbol colloquially known as the Jesus fish, to represent eyes. The Ichthus represents fertility in pre-Christian mythology, and baptism in Christianity. 
These religious symbols represent the holy land on which Jesus performed his first miracle. Though Naji el-Ali was a Muslim, he uses Christian symbols to represent Lebanon. The tears in these Ichthus eyes allude to baptism water which should purify, clean, and deliver the land from the hands of the enemy.

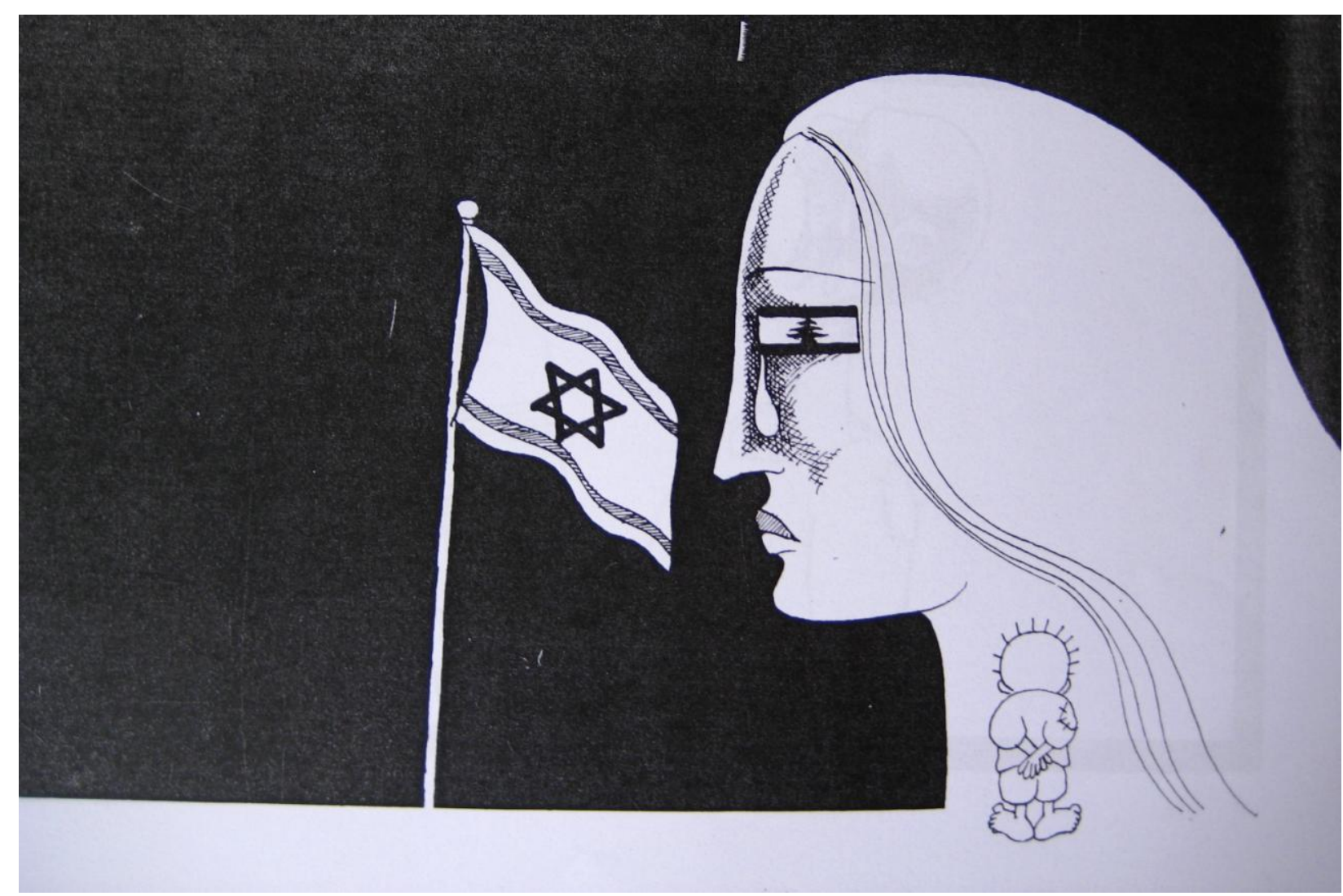

Figure 3

Figure 3 presents a woman with a Lebanese flag for an eye which is tearing at the sight of the hoisted Israeli flag. A symbol of Lebanon substitutes for the eye with a single tear falling from the flag. Interestingly, Lebanon, as a word, is often referred to in the masculine voice. However, the country is being represented as a silent woman conveying resistance through her tears. Nevertheless, such images do not invoke pity but rather disclose ethical resistance.

The images of saint-like women or mothers appear in many of el-Ali's cartoons to represent patience and hope. El-Ali mentions in his memoirs that when houses were destroyed by the Israelis and the men of the camps were arrested, the women were the ones 
who rebuilt the houses to shelter their children. Women, to him, represented endurance and resistance (Kallam 44). Most of the Palestinian women in Ain el-Helwi had relentless hope of returning to their houses in Palestine including his mother who wore her house key around her neck till the day she died (The Life and Death of Naji el-Ali). Ghanem Ghabash mentions in his article "هددوني بالقتل" ("They threatened to kill me") that the eyes of el-Ali's wife are those of Fatima, the female who appears in most of el-Ali's cartoons (43). The teary eye recurs in el-Ali's cartoons as a baptismal drop of water which cleanses and reinvigorates at the same time. The nourishing mother figure feeds with her tears. This represents the highest form of devotion, grace, and altruism. In one of his caricatures which isn't featured here due to its irrelevance to motifs, a dying woman asks Hanzala not to cry so that Arab regimes do not satirize them (Kallam 38).

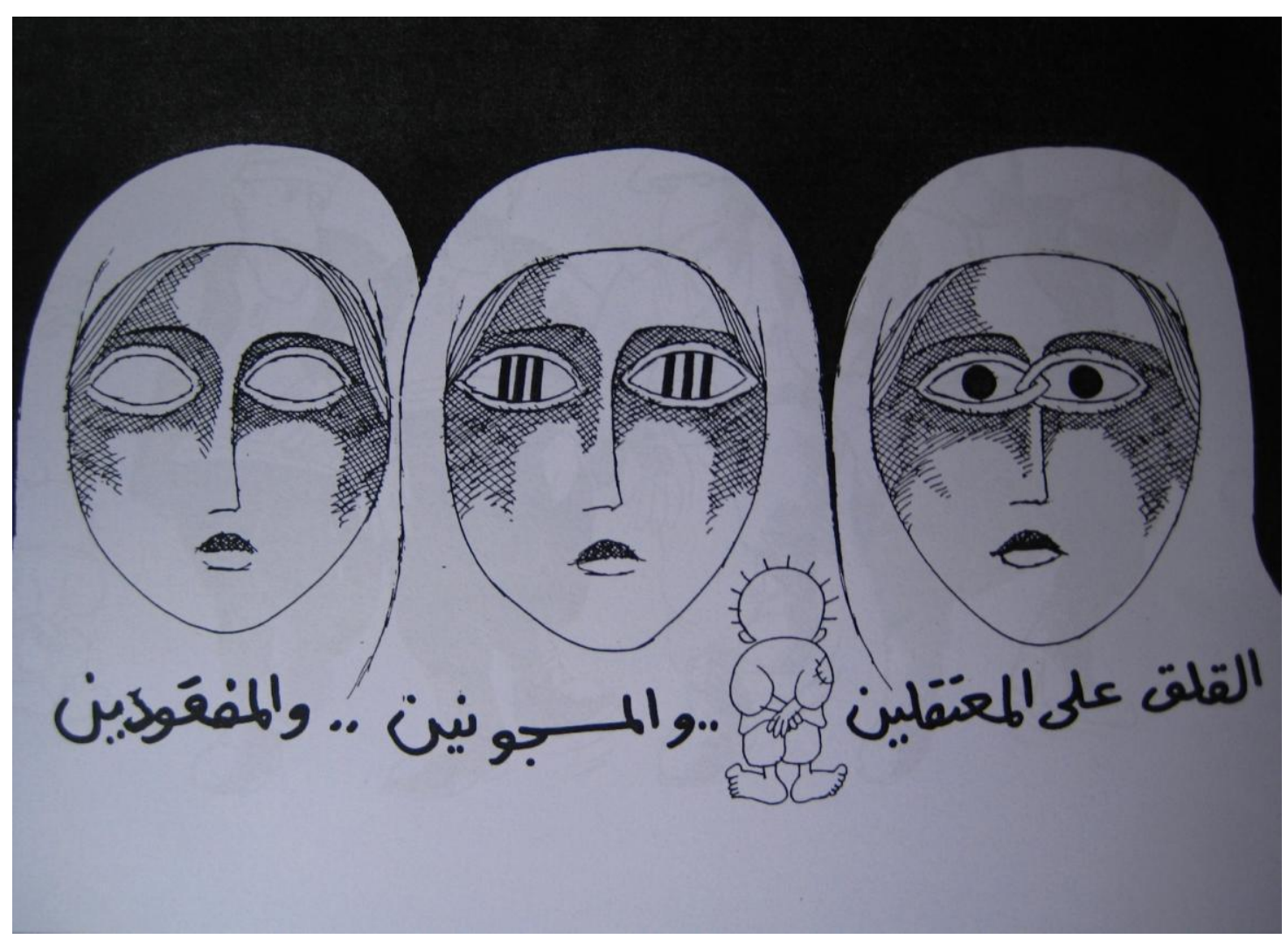

\section{Figure 4}

El-Ali particularly calls on eyes to show struggle as well as resistance. Figure 4 displays three veiled women with eyes altered to depict their anguish over their ordeal. The caption translates as follows: "anguish over the arrested, the imprisoned, and the missing." 
The eyes in the first picture intertwine to represent handcuffs of the arrested, while the second picture has prison bars in place of pupils thus depicting prisons. The missing pupils in the third picture represents the "missing," and the entire cartoon represents mothers, wives, sisters, and daughters of these men. In slang Arabic, pupils of eyes represent the dearly beloved. The endearing reference to a beloved one as "bu' bu' 'eini" to mean "the pupil of my eye" is popular in colloquial Arabic. These three women have pursed lips and utter nothing, but their worry for their men literally shows in their eyes. As previously mentioned, el-Ali sought to represent what he "saw confined in the eyes."

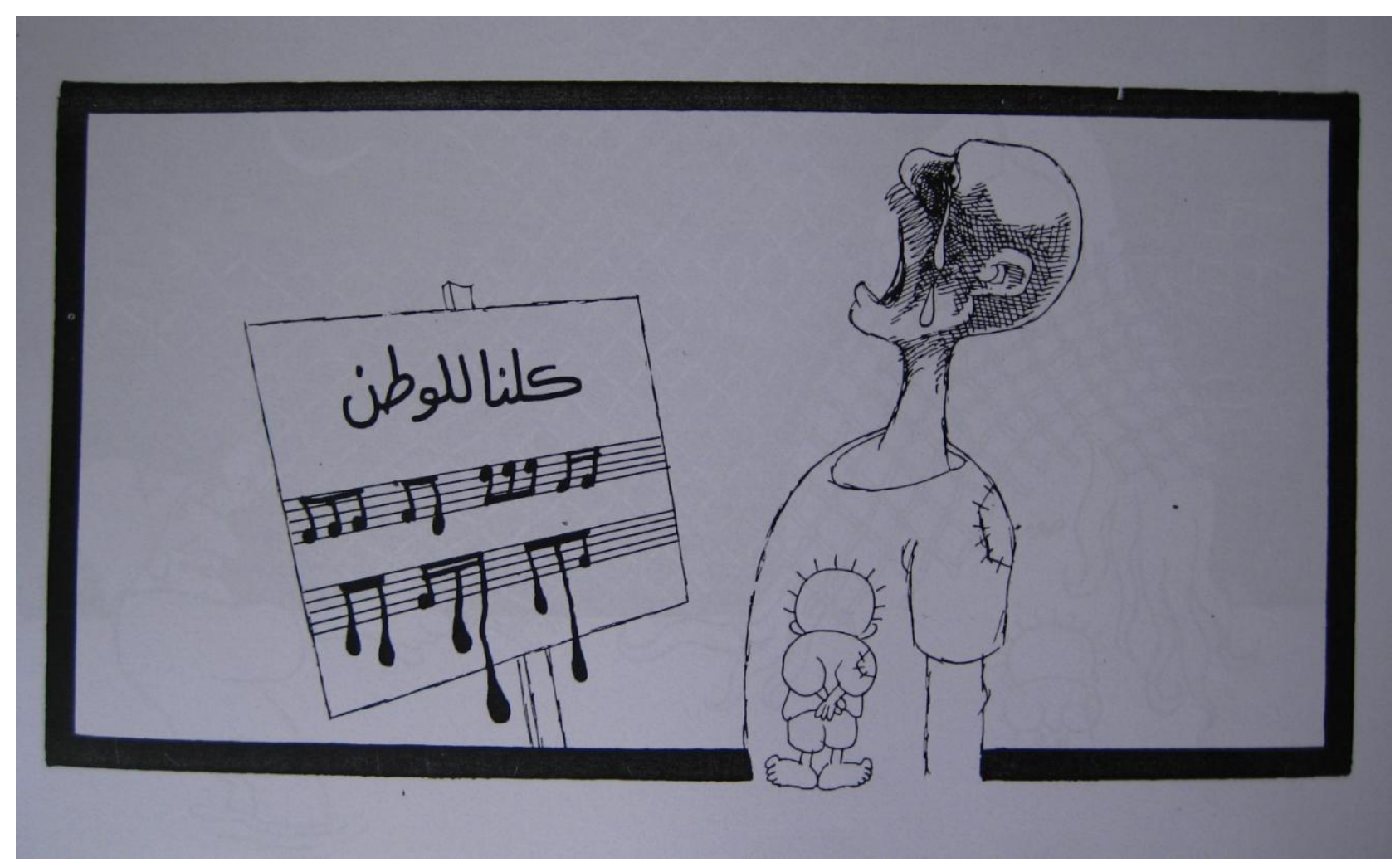

\section{Figure 5}

So far, eye motifs seem to appear in pictures with women only, but Naji el-Ali occasionally includes this motif in pictures representing men. However, the men with missing eyes aren't crying in silence, but often seem as if they are screaming in agony. Figure 5 represents a man crying out the Lebanese National Anthem. The musical notes bleed, and his eyes tear. The caption reads the first two words of the anthem "we are all for the nation." These tears do not seem to have a soothing or cleansing effect as the tears of the women in 
previous cartoons have, but represent the agony of a Lebanese man crying over his bleeding nation.

Another cartoon (figure 6) shows Hanzala, who almost always has his back to the onlooker and never exposes his face, depicted face on with a barbwire across his face and covering his eyes. The barbwire, in this case, presents the image of the oppressed person living in the confinement of a camp. They cover the eyes to show that Hanzala will always view things from an oppressed perspective, for Naji el-Ali considered himself an eye-witness to the atrocities committed against his people. He once stated that Hanzala isn't of one nationality, but rather a representative of all Arabs. Naji el-Ali asserts the ideological identity of Hanzala by describing him as follows:

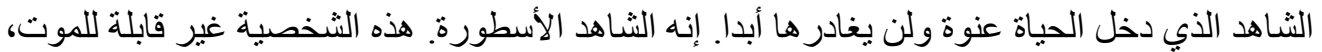

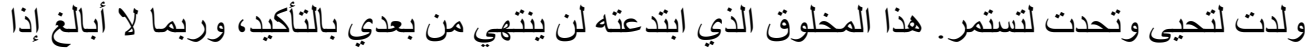

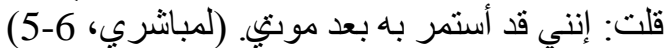

$\mathrm{He}$ is the witness who entered this life on purpose and will never leave it. $\mathrm{He}$ is the legendary immortal witness who was born to live and challenged to continue. This creature whom I created will not end after I die for sure, and I am not exaggerating when I say that I will continue through him after my death.

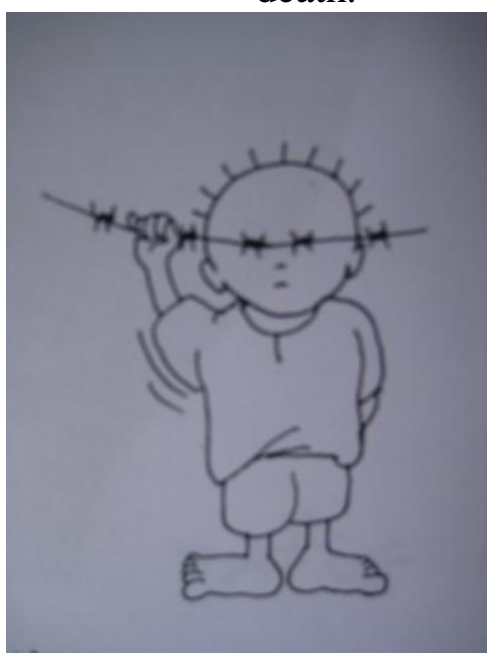

\section{Figure 6}

Naji el-Ali's cartoons also show evident marks of oppression through the graphic "foot" motif which he uses to express the absence of power. Planting one's foot firmly in the ground is a sign of power; being able to stand up in the face of one's enemy is also a verbal translation of resistance, and both statements exist in colloquial Arabic with the same 
meaning as their English counterparts (يلبط بالأرض، يقف في وجه العدو). Images of shoeless oppressed people appear frequently in el-Ali's caricature; in contradistinction, the hostile military men wear heavy duty shoes, and often tramp down the oppressed (Fig. 7).

Throughout history, being taller represented higher social stance. As a result, aristocratic women wore heels and commoners bowed to their superiors. Later on, men greeted others by the removal of their hats in order to show respect (Pearse). Shoes, therefore, become a sign of superiority among barefoot people, and the human who cannot stand up in the face of the enemy gets graphically represented in Naji el-Ali cartoons.

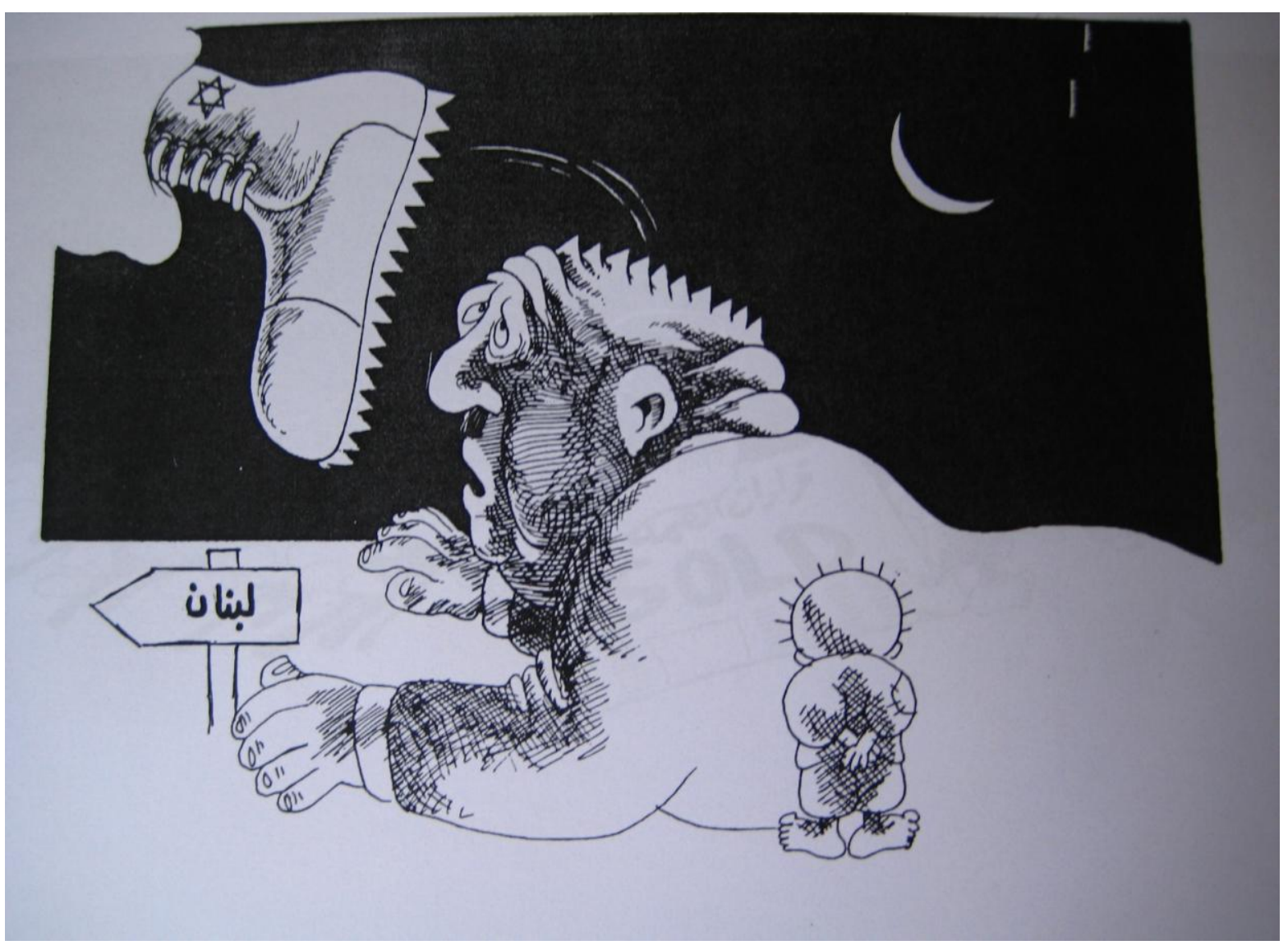

Figure 7

Naji el-Ali frequently blamed the Arab regimes for rendering people incapable to face the Israeli enemy, and received numerous threats for that. In his article " وظيفة فن الكاريكاتور "الأساس ... ناجي العلي نموذجأ ("The Main Job of Caricature . . . Naji el-Ali as Prototype”), Mustafa Limbashiri states, in one of the very few studies on Arabic caricature that Naji el-Ali refused to appeal to pity but chose the rhetoric of conscience which he knew would better 
serve the message of resistance. Though many of his cartoons represent helpless people, they do not aim at invoking pity but rather to represent the real situation of the people who have to endure in silence.

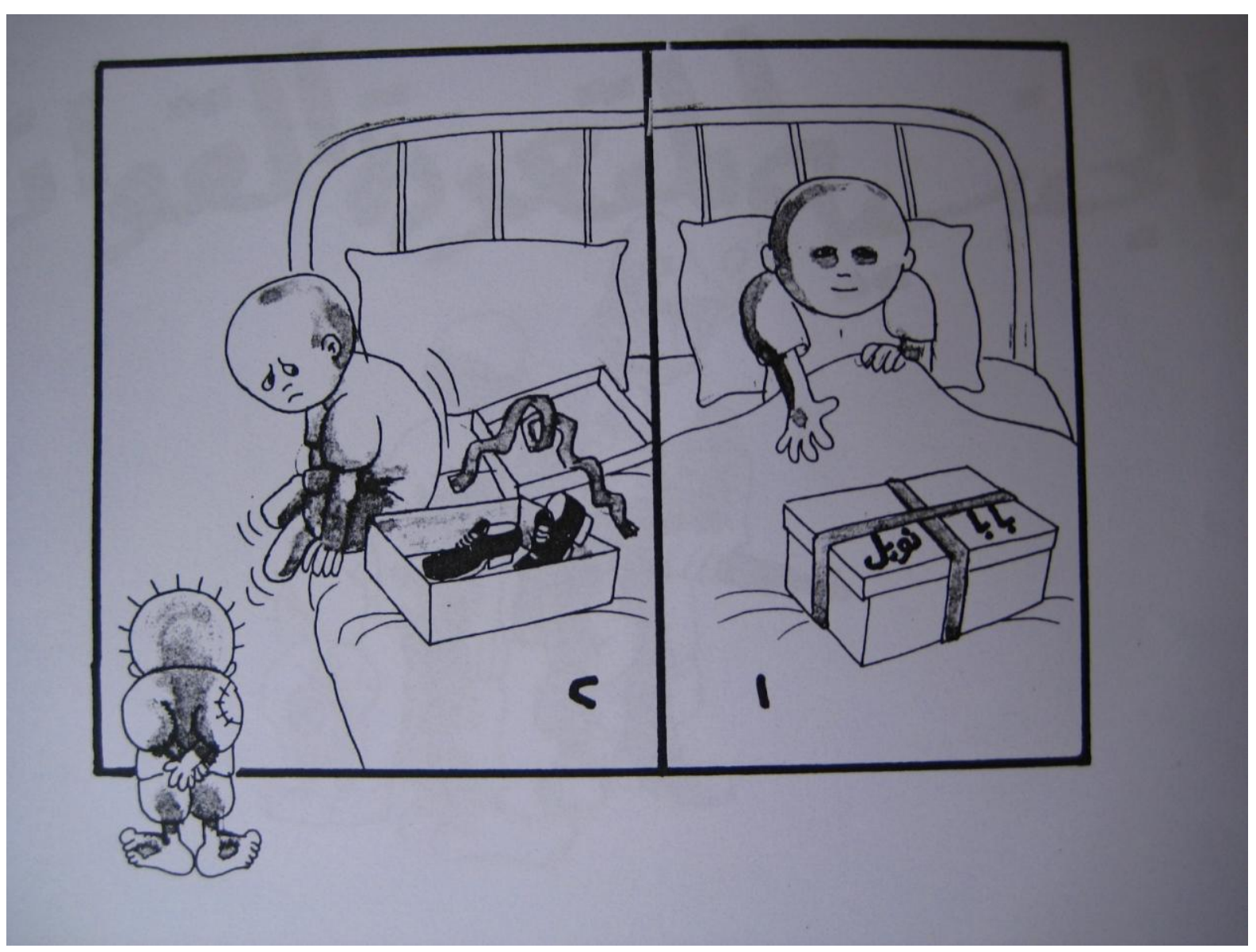

Figure 8

Hanzala, who was created to represent the struggling Arab people, is barefoot. He is never seen wearing shoes of any kind. He stands observing the atrocities committed against his people and holds his hands behind his back to convey rejection of what he witnesses. Sometimes Hanzala raises his arms and clenched fists in defiance, especially in cartoons which succeeded the Israeli invasion of Lebanon. Other children are also with wounded or broken feet, and some have amputated legs as well. Figure 8 depicts a child who has just received a Christmas present from Santa Claus. He opens up the box to find shoes and looks down at his amputated feet. The Christmas present is a tool which can help him stand up and feel powerful, but his inability to even wear those shoes comes from the fact that he is forever 
powerless unlike Hanzala who still has his feet though he is barefoot. Shoes, in this context, represent power. They protect feet and enable them to tread any terrain. Shoeless feet are vulnerable and weak. They serve only one purpose: the ability to run quickly and hide; however, they do not assist their possessor in standing tall.

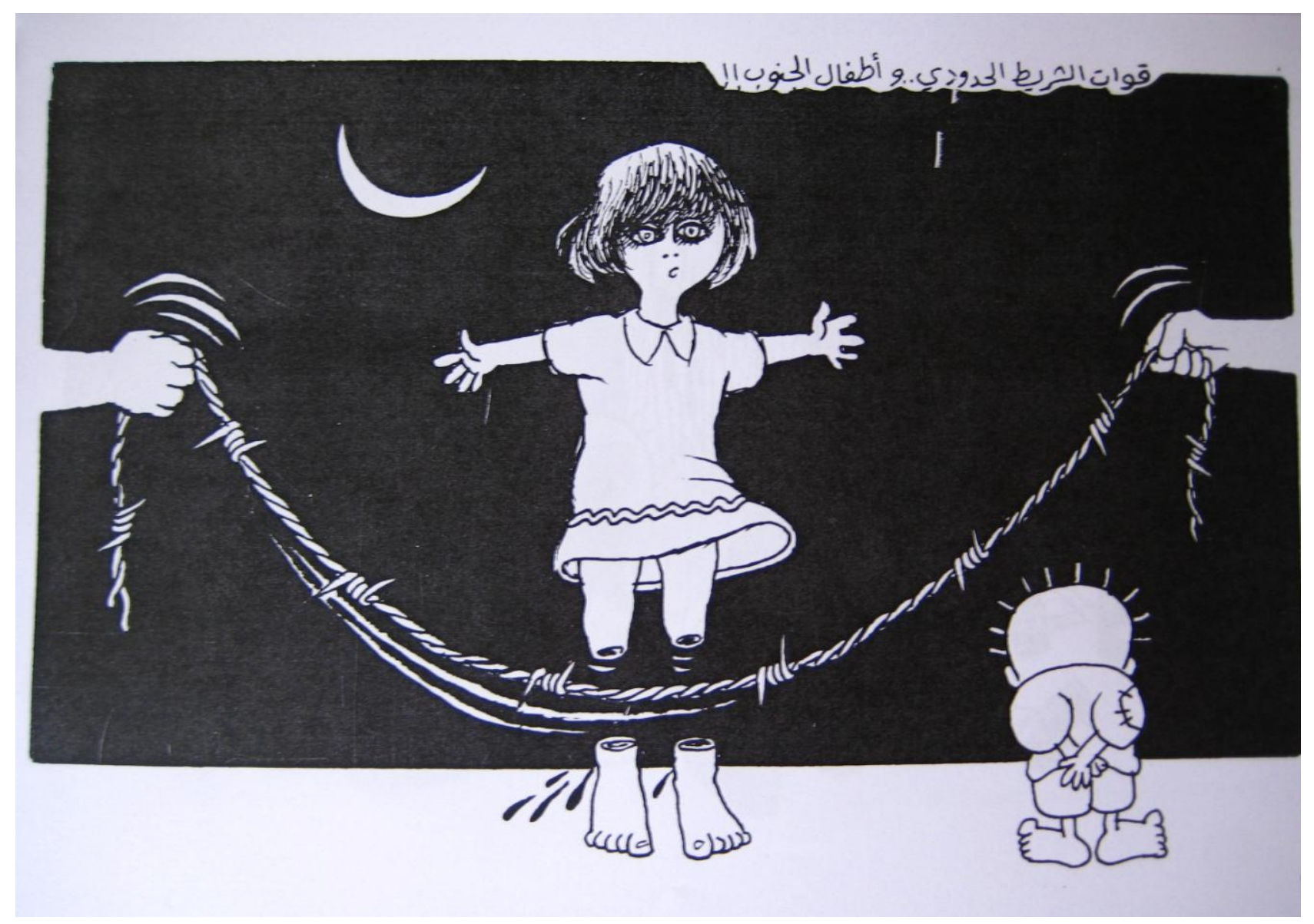

Figure 9

As previously mentioned, barbwires carry numerous symbolic meanings. They represent occupation, division, and oppression because they suppress freedoms. They limit, confine, and control. After Israeli forces withdrew from Beirut and the neighboring regions, they occupied the Southern part of Lebanon for nearly eighteen years ${ }^{9}$. Locals reported that

\footnotetext{
${ }^{9}$ Lebanese armed forces which were part of the Lebanese Army and which later broke off and collaborated with Israel were known as the Borderline Forces or kuwwat al-Shareet al-hududi lead first by Antoine Lahd then Saad Haddad. They controlled the area with the help of the Israeli forces.
} 
the Israelis used to plant bombs in toys causing children to loose limbs, and a recent report about this aired on the Lebanese Television confirming the matter (Tele Liban, 2009). Figure 9 displays a girl playing jump rope with a barbwire carried by members of the pro-Israeli Borderline Forces. The caption reads: "Borderline Forces and the Children of the South." In his memoirs, Naji el-Ali mentions that his daughter, Judy, received a serious injury from the shelling of these forces which left her in need for constant treatment for the rest of her life. However, this cartoon is not solely about Judy but includes all the children of the South be they Lebanese or Palestinian. Images condense into one picture to show suffrage of children growing up under occupation. Without her feet, the girl in the cartoon is deprived of the power to stand tall or be productive.

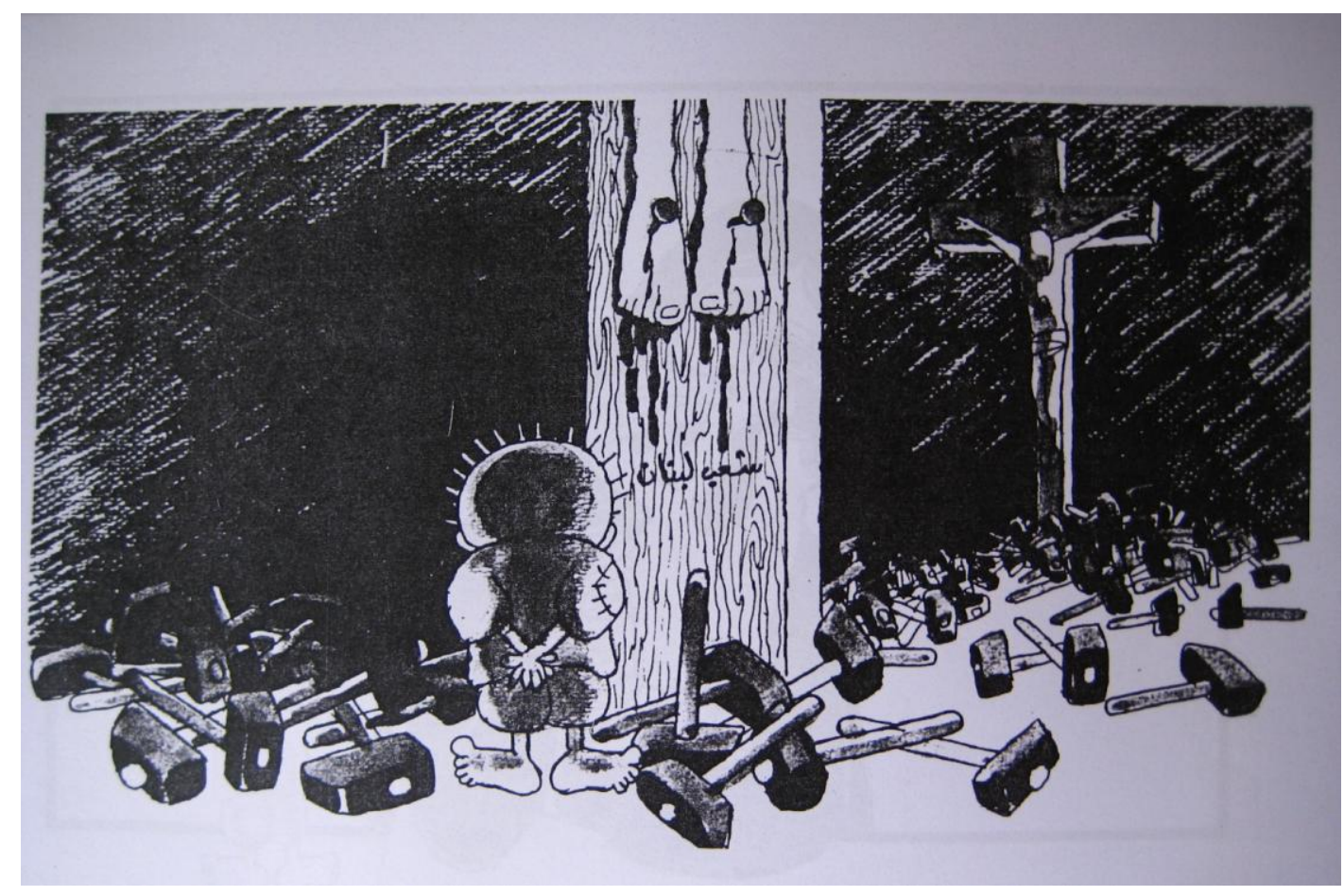

\section{Figure 10}

As with the eye motifs, Naji el-Ali incorporates Christian symbols in the cartoons depicting foot motifs. Figure 10 shows Hanzala standing in front of a crucifix among countless hammers. Only the feet of the crucified appear and underneath them the words "The People of Lebanon." The powerful crucifixion image depicts the struggles of the people in a drastic manner. As previously mentioned, el-Ali frequently uses Christian images. He 
was born in village claimed to have the tree under which Christ used to rest, and the memory of his hometown remained vivid in his mind throughout his life (Limbashiri 3).

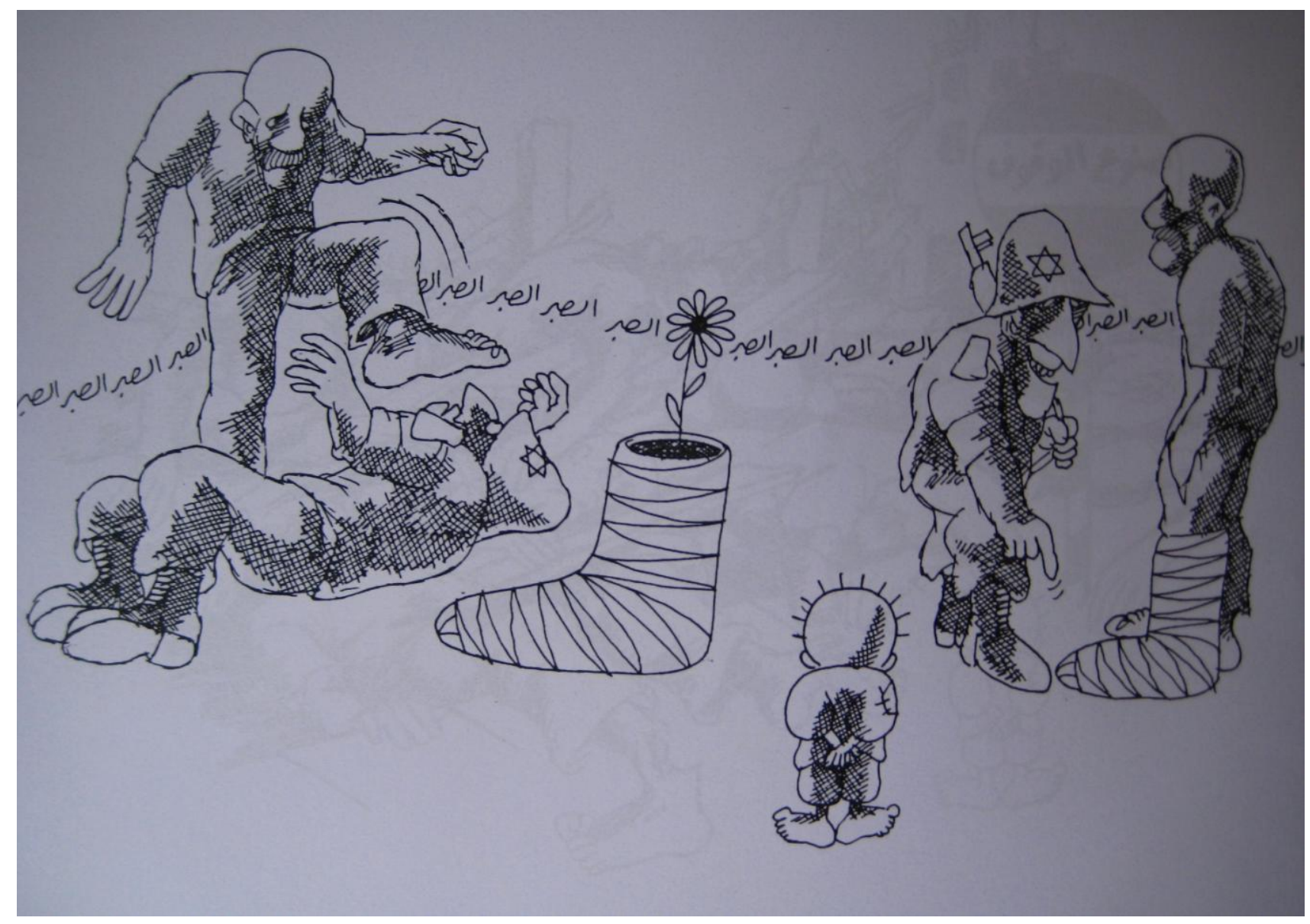

\section{Figure 11}

The serenity and beauty of his village, as he remembers it, became personified in the

Messiah, and the image of violation of his land became closely attached to the suffering of

Christ. Naji el-Ali states:

$$
\begin{aligned}
& \text { المسيح يعنيني كقيمة للفداء ولقد رسمته كثير آ، ليس لأنه فلسطيني بل لأنه كان مطارداً ومغلوبأ وهو النبي. }
\end{aligned}
$$

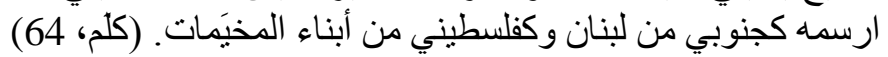

The Messiah concerns me with his sacrificial value and I've drawn him a lot, not because he is Palestinian but because he was chased and defeated and he is the Prophet. I drew him as a Southerner from Lebanon and as a Palestinian from the camps.

While most of Naji el-Ali's cartoons show suffering at the hands of the Israelis, very

few show resistance. One of his most striking drawings depicts a man who removes the cast

off his foot and stomps on an Israeli soldier after the latter laughingly points at his broken

foot (figure 11). The word "patience" in the back contrasts with the deed. The flower planted 
in his cast may symbolize hope which acts as a motivation to endure the humiliation of occupation. The deed contrasts with the caption, and it rarely occur in el-Ali's cartoons. While Arab regimes were preaching patience, Naji el-Ali saw the need for resistance, under any circumstance, crucial and necessary. He states that he has never held a gun in his life and that he is not a military man, but admits that had there been proper resistance, Israel would have heavily lost in its invasion of Lebanon (Kallam 36-37). When ethical resistance fails and when patience runs out, a need for a more pronounced form of resistance might be necessary as this last caricature declares.

Irish caricatures present a message of moral resistance in the form of visual artistic expression. Perhaps the most interesting aspect about Irish caricature is that it was first cartooned by non-Irish caricaturists in English magazines. This makes the analysis process a much more complicated one because it seems that while the Irish were engrossed in battling oppression, tithe, sectarian segregation, and famine, British, French, Germans, and Americans were drawing caricatures about them. Historically, caricatures became prominent in England around the $17^{\text {th }}$ century and illustrated the highly complicated Irish struggle under the British rule. Not until the 1870s did cartoons by Irish cartoonists start appearing in Dublin-based newspapers and magazines. They produced work of high quality and were aimed at the educated readership (Douglas 88).Those Irish caricatures, which came centuries later, looked a lot like their European counterparts. Though they were presumably influenced by the British cartoons, they contained foot and eye motifs which pronounced oppression.

Numerous studies which use American, Irish, European, and British caricature to highlight Anglo-Irish relations were conducted by Hollander, Douglas, Harte, O’Hara, and others. These recent studies rely on caricature and cartoons for historical and cultural analysis. Joel Hollander's Coloured Political Lithographs as Irish Propaganda uses Irish political cartoons of the late nineteenth century published in newspapers and periodicals to show how it shaped the public opinion during Parnell's struggle to lead the Irish into Home 
Rule between 1879 and 1886. It discusses Gillray's earlier physiognomic models which displayed the Fenians as apes in the English satirical journal Punch. Drawing Conclusions: A Cartoon History of Anglo-Irish Relations by Douglas, Harte, and O'Hara's uses over 250 cartoons from different sources to write the history of the Anglo-Irish relations.

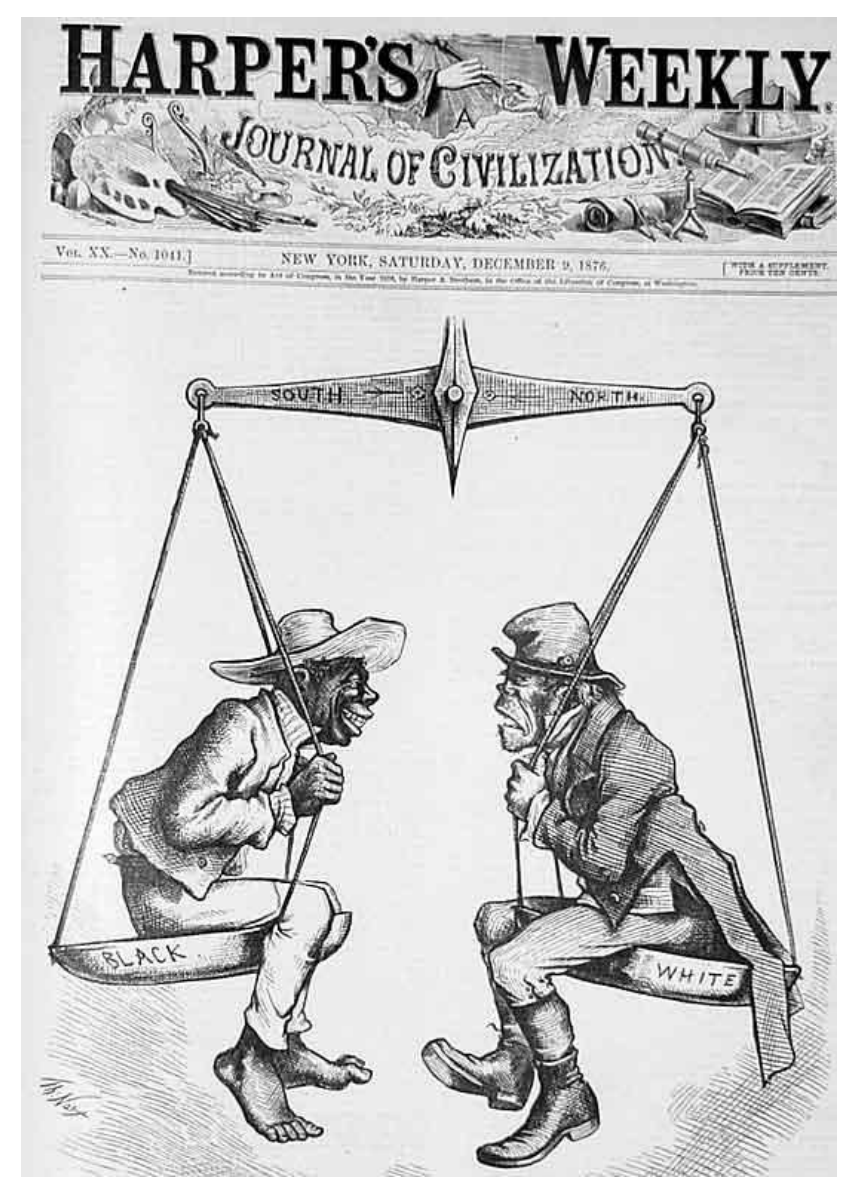

\section{Figure 12}

Molding public opinion through cartoons became popular in the United States during World War I when the government established a Bureau of Cartoons to "mobilize and direct the scattered cartoon power of the country for constructive war work" (Kemnitz 86). Some of these images portray the Irish as barbaric and ape-like. English cartoons showed the attitude of the British towards the Irish especially in Sir John Tenniel's cartoons which portrayed the 
Irish as apes, and which compared them to the slaves of Southern United States ${ }^{10}$. The humiliation to both races sprung from a scientific folklore of physiognomy in the midVictorian period, and studied by L.P. Curtis in Apes and Angels: The Irishmen in Victorian Caricature.

The ability to judge human character from facial features renders Tenniel's juxtaposition of the Irish and apes more than mere humiliation to the former. Tenniel influenced the English public and drove them to associate the Irish with animals from which humans evolved according to Darwin's Theory of Evolution. Being backwards, barbaric, and uncivilized became an image associated with the Irish. This aided in British underestimation of the Irish and their need for a Home Rule which they had struggled to achieve for centuries. Additionally, to view someone as barbaric and backwards triggers a need to tame and control this beast. Therefore, it does not come as a surprise that the British did not feel compelled towards granting Ireland its independence or merely a Home Rule until almost two centuries later. Punch's cartoons were designed to trigger hatred and sustain "civilian enthusiasm" against the Irish. Comparing the Irish to apes and to the Slaves of the South meant rendering them in need of control and taming.

As previously mentioned, Irish cartoons, which came centuries after their British counterparts, appeared to be a reaction to the latter. John Tenniel, known for his illustrations of Alice in Wonderland, frequently depicted Ireland in his Punch cartoons as Hibernia, Britannia's younger sister which has been ravaged and controlled by barbaric Fenians. The Irish cartoonists later changed Hibernia's Latin name to Erin, the poetic name for Ireland, and depicted her as controlled by Britain. Figure 13 shows a restrained and gagged Erin tied to the pole of Coercion, while William Gladstone, who served as Liberal prime minister four times and supported Irish home rule, debates which shamrock he ought to hand to her.

\footnotetext{
${ }^{10}$ In his article published on March 10, 2010 and titled "How the Irish Became White," Art McDonald mentions that the Irish in the United States were commonly refered to as "negroes turned inside out" while African Americans were called "smoked Irish."
} 
Despite Gladstone's good intentions towards Ireland, O'Hea ${ }^{11}$ cartoons Gladstone as more inclined to hand Erin the shamrock of force, famine, and failure, instead of the Land League demands of fair rent, fixity of tenure, and free sale. Gladstone did grant, five months later, the rights to the Catholics with his Land Act; however, skeptical O'Hea had cartooned Erin enslaved with chains around her ankles. Her arms appear to be restrained by a rope, and her mouth covered with a piece of cloth, while her ankles are shackled with metal. Her lowered head and closed eyes while she awaits the verdict do not represent a yield to authority but are rather a bodily pronunciation of the word on the pole to which she is bound: "COERCION." Erin, coerced by cloth, rope, and metal, did not give in to the Coercion Act of 1881 in spite the arrest of all its principal leaders. She represented, in her barefoot stance, resistance because of the numerous rebellious forces, leagues, and unions of her people against British hegemony.

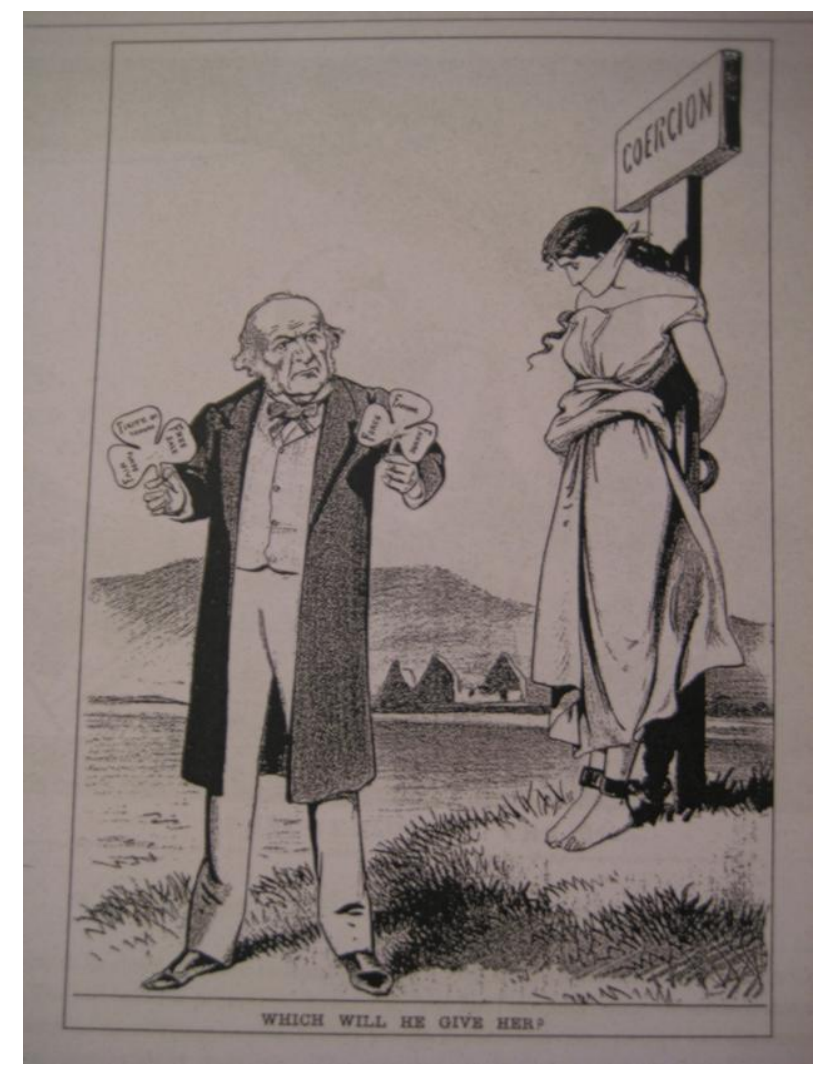

\section{Figure 13}

\footnotetext{
${ }^{11}$ John Fergus O'Hea was an Irish political cartoonist and founder of Ireland's Eye. Gladstone described his pencil as "directly guided by a spirit of patriotism" (Hollander 19-20).
} 
Irish cartoons frequently speak about British oppression or their direct control of the Irish affairs. Figure 14 shows Gladstone towering over Parnell the Irish nationalist leader who served as a member of the British parliament and led Ireland's Home Rule Movement. The caption reads: "Shut your eyes and open your mouth, and take what I will give you." Gladstone carries a folded paper which reads "subordinate parliament." Though Parnell passed away in 1891, the cartoon which appeared in the United Ireland newspaper in 1892 alludes to Gladstone's questionable enthusiasm for the implementation of the Home Rule. Gladstone had made agreements with Parnell to cancel the coercion acts in 1882 in return for ending the political agitation (Moody 240). Though United Ireland had once belonged to Parnell, it split between Parnellites and anti-Parnellites after his scandalous affair with the wife of Captain O'Shea, a former member of the home rule party. Powerful Parnell, who was once viewed as the decisive man pushing for the liberation of Ireland through the implementation of the Home Rule Act, is portrayed in the outfit of a little girl with shut eyes, taking anything from Gladstone who in turn is wickedly trying to pass a "subordinate parliament." Though history proved the good intention of Gladstone, some Irish remained incredulous regarding his motives. The shut eyes represent submission to the authority of the British regardless of how enthusiastic the latter appeared to be regarding the independence of the former. Additionally, Parnell's affair rendered the Irish Catholics hostile towards him because of its scandalous nature. Hence, the conservative Irish viewed him as a subordinate to Gladstone in parliament and regarding Irish affairs. 


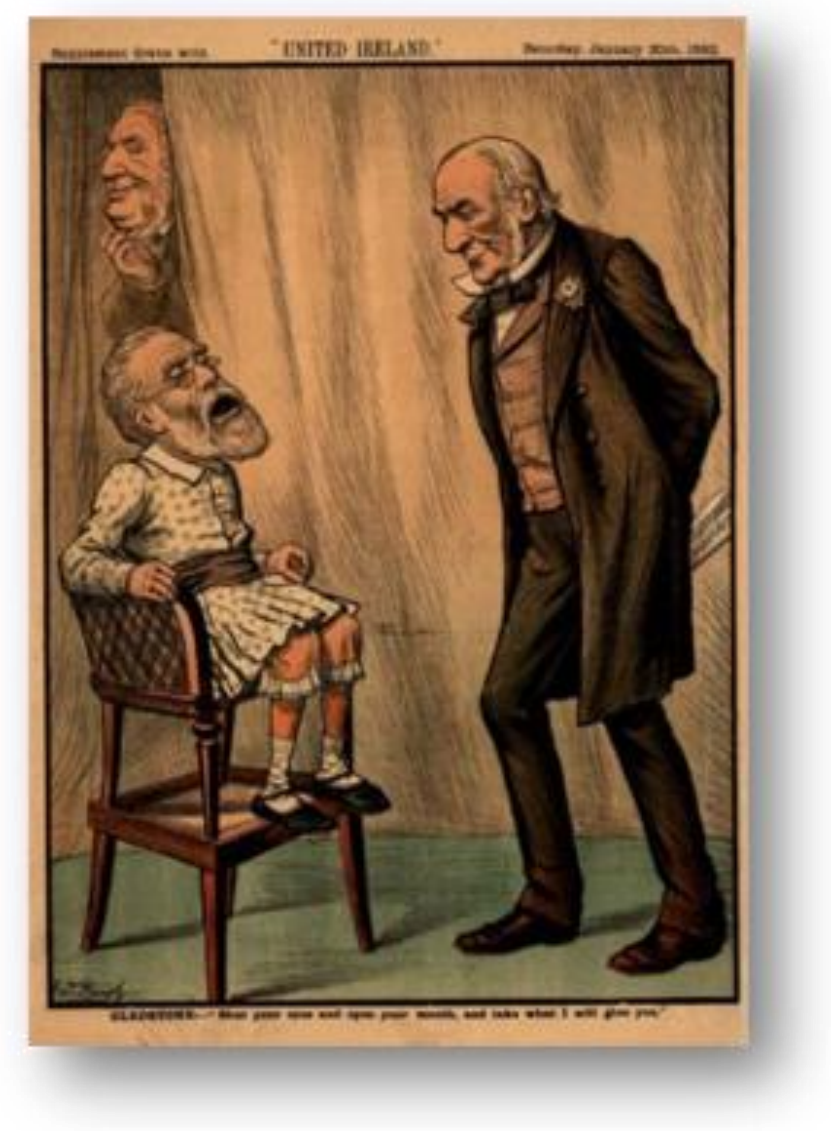

\section{Figure 14}

Foot motifs appeared in the cartoons of the Irish even when the feud was among them and not only with their oppressor, especially since they focused on the losses rather than on their state of enmity. The leader of the IRA in the Maze prison, Bobby Sands, began a hunger strike in March of 1981 aimed at securing for republican prisoners the political status which they were deprived of in 1976. Gradually, other prisoners joined. As a result, Sands obtained 30,492 votes thus defeating his Ulster Unionist opponent Harry West. This greatly increased the pressure on the British to concede and accommodate the nationalists. As a result, the Daily Mail cartoon (figure 15) shows the resentment towards this win by the IRA and seeks to remind the public of the victims of the IRA violence (Douglas et al). The missing leg represented the political losses of an entire segment of people and the oppression of an enemy. 


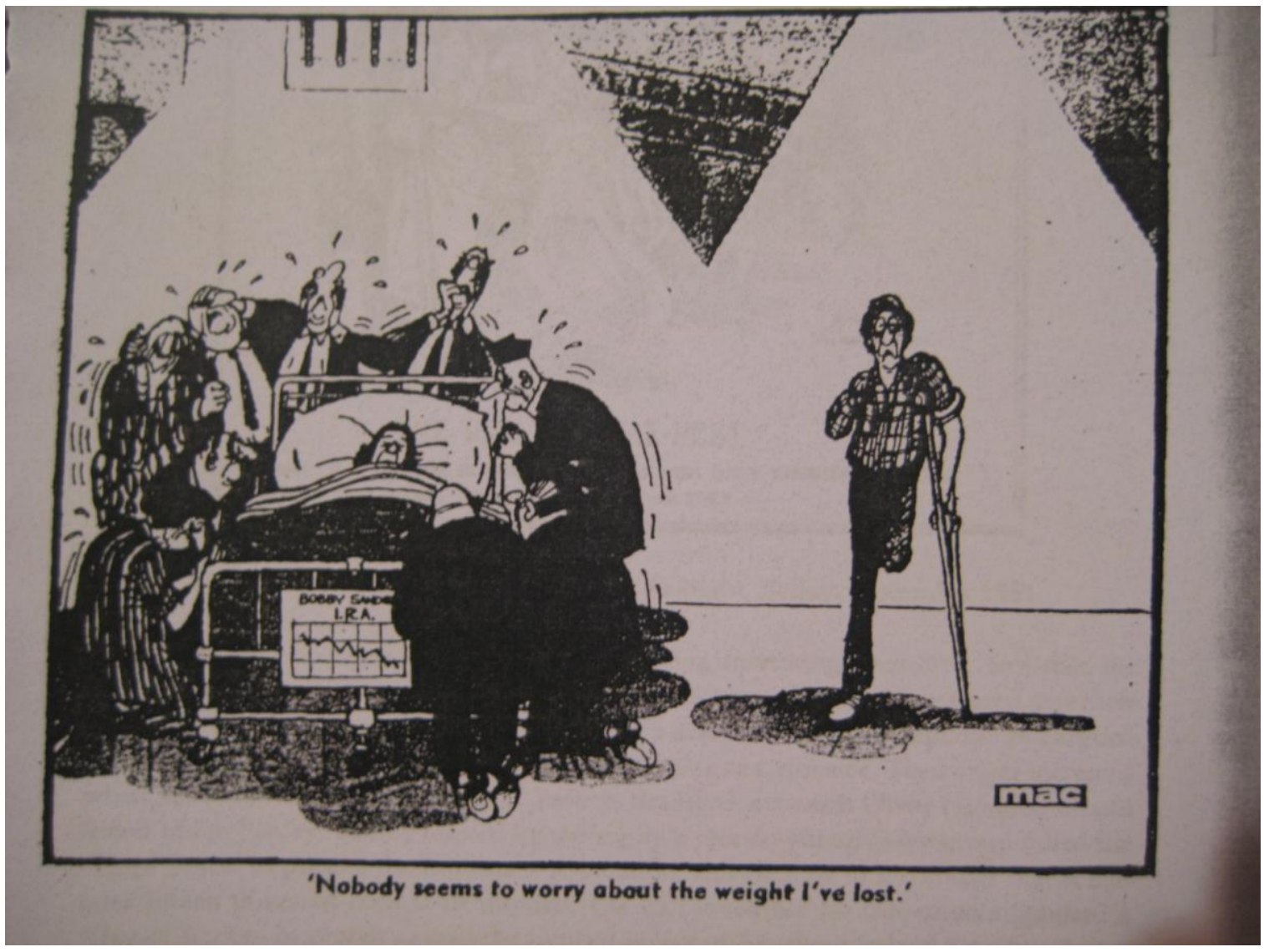

\section{Figure 15}

Another cartoon by Martyn Turner depicts the deep running hostility between the Catholic and Protestant Irish in Northern England. Figure 16 depicts two men: one belonging to the Irish Republican Army which is pro a united Ireland, and the other to the Ulster

Defense Association which is pro a Northern Ireland state belonging to Britain. The UDA declared ceasefire in August of 1994 and was followed suit by the IRA in October, allowing

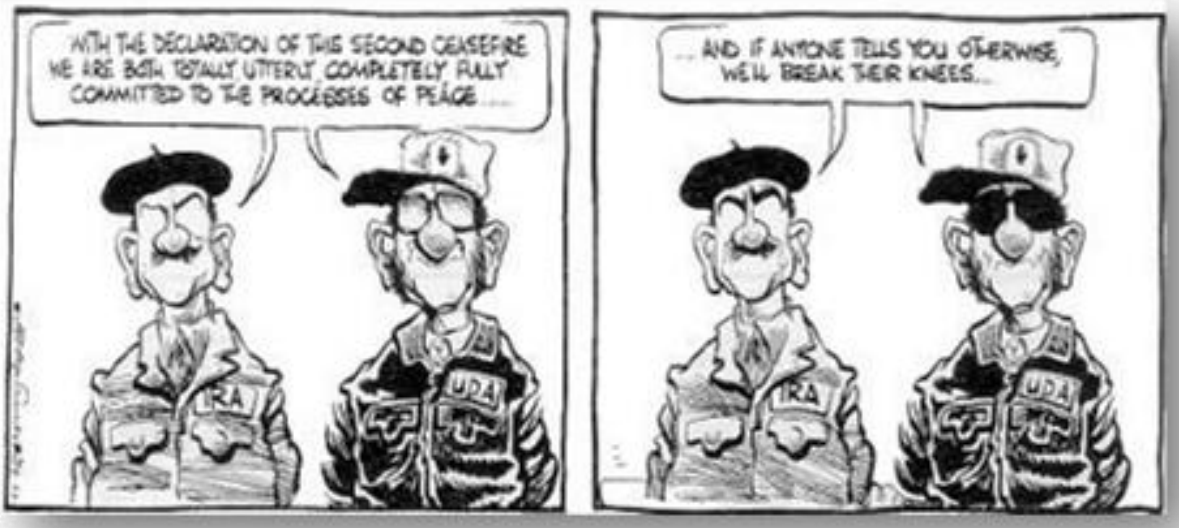


the British and the Irish governments to enter a direct political dialogue away from armed hostility. The IRA member appears without eyes while the UDA member wears glasses. The first caption reads: "With the declaration of this second ceasefire we are both totally, utterly, completely, fully committed to the processes of peace," and the cartoon shows the UDA member with a smile on his face. However, the second caption reads: "...And if anyone tells you otherwise, we'll break their knees." With this, the glasses of the UDA member become shaded and the smile is wiped off his face. The second caption ridicules the deep running hostility of both parties who threaten to break the knees of those who might doubt their good intentions. The cartoonist satirizes the use of violence in attaining peace and independence. Nevertheless, breaking knees symbolizes stripping someone of power by rendering him unable to stand up on his legs. Additionally, the absence of pupils from the eyes of the IRA member alludes to his resistance because history has taught him that the sword is mightier than the word. Moreover, the glasses of the UDA member turn into shades in the second section of the cartoon to mean that if need arises, he will shut down channels of negotiation and resort to using power. The irony lies in the fact that both forces agree on the same words yet cannot agree in words to cease fighting against each other. They agree to disagree about the fate of Ireland. The IRA bombings in Northern Ireland in 2009 show that dormant IRA hasn't lost hope in uniting the north with the south. It continues its endeavor to unite the country under one flag after centuries of divisions and oppression imposed on Ireland by England.

The approach to history through the usage of cartoons became popular in the $1900 \mathrm{~s}$ and was explored by Spielmann. In his article The Cartoon as a Historical Source, Thomas Milton Kemnitz stresses the importance of cartoon in providing historical information about the social and personal attitudes towards political issues:

[Cartoon] provides little insight into the intellectual bases of opinion-for which the historian usually has better sources - but it can illuminate underlying attitudes. Not only can cartoons provide insight into the depth of emotions surrounding attitudes, but 
also into the assumptions and illusions on which opinions are formed. They remind the historian of the importance contemporaries placed on seemingly insignificant events and of the relation between these occurrences, popular attitudes, and public opinion. (86)

Irish caricatures containes some foot and eye motifs with a message of oppression different from the cartoons of Naji el-Ali, but which stand out as representatives of oppression and rebellion nevertheless. Though the motifs of eyes and feet which appear in the cartoons of Naji el-Ali might not exactly appear in Irish caricatures, both, as visual mediums, play a role in voicing rebellion.

Cartoon, a visual medium, reaches a larger number of people. Even those who cannot read understand the cartoon, given that they understand its context. Naji el-Ali's cartoons represent his trauma through motifs which voice the silent cry of his oppression. As a result, his cartoons transcend borders and this silent outcry can be recognized by many.

"Decapitated heads function as deceptive fragments of a larger truth," states Banta, and "Fragments are spattered across the caricaturist's page, bodily parts dismembered in the name of realizing the ideal sublime unity" $(39,54)$. Motifs in caricature may be subtle signs which cannot be picked up instantly by the onlooker and understood in their universality, but studies about the psychology of cartoons explain how an onlooker unconsciously relate to those motifs by explaining how these motifs are produced in the first place.

Political cartoons carry an ephemeral political message which loses its meaning and impact with political change; however, a residue of resistance to injustice often remains as in the case of the cartoons discussed in this chapter. Kemnitz describes cartoons in his article "The Cartoon as a Historical Source" as follows:

[Cartoons] can match any other media for invective and is an excellent method for disseminating highly emotional attitudes. It has been employed frequently and effectively as an aid in building up resistance to the policies of politicians and as a weapon of propaganda generally in ridicule. The cartoon also is an ideal medium for suggesting what cannot be said by the printed world. (84) 
If cartoons can suggest what cannot be told in writing, then cartoons can escape scrutiny and condemnation. Additionally, cartoons play a "double telling" role: "the unbearable story of its past and the unbearable story of its survival," as Banta puts it (8).

The social implications of political cartoons are concerned mostly with the background of the cartoonist: his identity, social belongingness, affiliation, and education. In the case of Naji el-Ali, excerpts from his diary help shed the light on why his caricatures are laden with motifs of eyes and feet. The social context of the cartoons plays a vital role in the understanding of these cartoons. Taken out of context, cartoons can sometimes loose their meaning. In his article "Observations on a Theory of Political Caricature," W.A. Coupe stresses the importance of understanding all the aspects which shape political caricature. He states:

[A] theoretical understanding of political caricature involves an understanding of caricature itself, the caricaturist, his publisher and audience, and the historical epoch and social structure within which the caricaturist operates. (79)

Nevertheless, these cartoons can sometimes be understood especially when the political dilemmas addressed by the cartoon persist. The generality of the theme renders the cartoons sometimes even timeless.

The interdependence of the social, political, and psychological implications of cartoons renders analyzing them more complicated, but this interdependence plays a crucial role in showing how these cartoons might have been shaped and by what factors. In his book Psychology of the Image, Michael Forrester better explains the interdependence of these different factors which shape production:

Perceptual experience and mental imagery are interdependently embedded within our social-cultural, and particularly linguistic, practices. With language we construct narratives, accounts and descriptions about all that is said to be external and internal to human perception. (29)

The political cartoonist, in general, uses visual language in order to communicate the social struggles under political tyranny. The aspects affecting production of the art should be 
studied as a whole. In "Seeing Metaphor as Caricature" Worth states that "a caricature, like a picture, is neither true nor false but, like a metaphor, is a structure that reveals a set of meanings intended to communicate a certain set of relationships within some understood or understandable context and bounds" (204). Understanding social and cultural contexts aids in the understanding of political caricature, and failing to do so might lead to false interpretation. Nevertheless, it is difficult to assess the impact of a certain cartoon on a particular group of people during a particular time period, for "the situation becomes [more complicated] when we are dealing with readers culturally or historically remote from us" (Coupe 83).

The meaning of cartoons often crosses national borders and can be understood by different people unlike linguistic communication. This certainly depends on the transparency of the notions conveyed in these cartoons. Although social and political implications differ in cartoons, they, nevertheless, have similar psychological grounds uniting them such political repression and trauma ${ }^{12}$.

Regardless of how negative cartoons can be, they have an undeniably humorous though often punitory role to play. Coupe frequently talks in his article about the humorous qualities of a caricature. Caricature and cartoons are often expected to be funny and invoke laughter. However, the sarcastic quality of caricature renders it punitive. Streicher asserts the "negative" quality of caricature especially because it distorts. As Ernst Kris claims, caricature is negative because of its affinity with dark magic since it started precisely late $17^{\text {th }}$ century as an attack on the church (Coupe 86). Whether funny or destructive, they present the onlooker with a chance to vent some of his angry emotions at the situation presented in the cartoon. Laughter is a good coping mechanism, and when one realizes that he is not alone in

\footnotetext{
${ }^{12}$ Shrewsbury International Cartoon Festival and Boston International Cartoon Festival are two of many cartoon festivals which attract cartoonists from all over the world who utilize cartoons as their means of communication.
} 
his state of pain or anguish, one is comforted. If a cartoon does not make the onlooker laugh, its sometimes cherubic drawings help him strip the threat of its menacing properties.

Though Coupe explains how serious cartoons do not distort, he does not explain how it represents in childlike drawing very serious political and social material. The principles of caricature do not differ much from the principles of Freudian verbal wit. However, the primitive mechanism of aggressive impulse which underlies caricature made a very late appearance in the history of pictorial art as stated by Kris in "Principles of Caricature" (95). Kris explains that because art no longer meant "perfect craftsmanship, but vision," the caricaturist could freely express "a realization of a perfect deformity which reality could only hint at." Thus, the condensation of pictorial images which represent anger and aggression towards political oppression in simplified and childlike cartoons have strong penetration ability to the minds of human beings because of the simplicity of their images and the accessibility to their analysis. Clearly defined childlike images present onlookers with accessibility to analyze and interpret them since they present in a trivial image condensed ideas and can reach a vaster number of people than other pictorial images. Another possibility would be that the cartoonist escapes disturbing feelings of cultural oppression by mentally returning to an age when he seemed free of the responsibility of resistance and rebellion-his pre-teen years. In the case of Naji el-Ali, this time occurred when he was five years of age; the age him and his people were first subjected to Israeli oppression.

The cartoonist derives his images out of social, political, and cultural conventions. Through a complex psychological process, he produces. Whatever he perceives, we might perceive though unconsciously. Forrester states:

Arguably, within psychology there remains considerable ambiguity between what constitutes the 'inner' and the 'outer'... In perception, the 'incoming stimulus' on the retina is said to form the basis for emerging constructivist processes whereby we 'see' whatever is being perceived. What is 'outside' provides the basis for the 'inside' experience of perception. To 'see' is also to categorize, and yet what underpins or motivates categorical imposition on the sensory information is surely language, social practice, and cultural convention. (28) 
The complex intertwined process of perceiving and categorizing depending on numerous outside factors shape how viewers interact with a given cartoon. The highly emotional interaction based on visual understanding of motifs rather than the understanding of language makes cartooning a more popular medium of communication. As a result, the message conveyed influences a greater number of people, and simultaneously affects and shapes their outlook on events. The cartoonist voices rebellion, and with him, thousands other rebel against oppression. Whether through allegorical images or simple bodily motifs, a cartoon remains a silent voice which speaks through the medium of vision. 
The expression of the self through dance, poetry, and drawing becomes a tool of liberation from oppression when it serves resistance and rebellion. This thesis suggests the presence of a traumatic unsaid which seeks to express itself in aural, motile, and visual arts, and that art in oppressed cultures embed motifs of body parts such as eyes and feet to represent resistance and rebellion. These motifs exist regardless of place, time, culture, and language, and surface as a result of oppression.

This thesis highlights how these motifs have come to exist and for what purpose. Regardless of whether the language of the culture was suppressed or not, these motifs surface nonetheless. The tools of expression change: while the Lebanese feel more at ease in expressing their ordeal in simple colloquial Arabic, the Irish use the language of their oppressors in order to express their defiance.

Whether in Lebanese or Irish contexts, the motifs of eyes and feet appear to indicate the presence of a traumatic experience related to oppression of a culture. The Lebanese express themselves easily through oral poetry because their language was not suppressed by their oppressor, while the Irish wrote their war poems in a language native to their oppressor and not to them. The oral Lebanese Zajal defends Lebanon against invaders with images of eyes that fight and feet that offend. As Plato argues, a person can defend and explain his thoughts better than a text can (Ong 78). Oral poetry has a prophetic allure to it: The term "oracle" comes from the Latin ōrāculum or ōrāre which means to speak. As shown in some Lebanese poems, the speaker assumes a prophetic role especially when trying to impart wisdom upon his listeners by advising the Lebanese to unite against their oppressor. On the other hand, the Irish write poetry in a language native to their oppressors. Nevertheless, this "dead" medium, as Ong describes it, has a paradoxical quality to since it indicates the immortality of the text:

The paradox lies in the fact that the deadness of the text, its removal from the living human lifeworld, its rigid visual fixity, assures its endurance and its potential for being resurrected into limitless living contexts by a potentially infinite number of living readers. (80) 
Irish poetry about dream battles preserve collective memories which serve the message of resistance. Though these poems were written in English, the message of resistance surfaces in images of feet and eyes. In both cases, the poetry contains elements of expression which voice moral rebellion.

If motifs tell of resistance and rebellion, then a study of those motifs becomes necessary to understand embedded meaning in a poem, a dance, or a caricature - what was not directly said. The artistic expression escapes condemnation, scrutiny, and censorship by the oppressing force, and the oppressed finds an outlet through this form of expression.

While poetry rebels with words, dances free the bodies to express what is politically and socially censored. Stomping delivers a message of resistance and rebellion to oppression. As suggested in the thesis, the utilization of space and place combined with stomping and hoofing evidently express a message of rebellion in Irish and Lebanese dance formations and steps.

The similarities between Irish and Lebanese voicing of rebellion through artistic motifs includes cartoons as well. The silent cries of oppression manifest themselves in bare feet and eyes in Naji el-Ali's cartoons as well as those of different Irish cartoonists. Bare feet stand for the powerlessness of the oppressed while eyes carry a message of resistance.

The similarities between both cultures are striking for both countries have endured a similar history of oppression for centuries. Therefore, a claim that oppression results in similar forms of expression bound by specific motifs seems to be in place.

This thesis bridges literature, dance, and caricature studies, and contributes to the three fields by suggesting an unexplored area related to voice and motifs in each of the three fields. Since the field of caricature is regaining its momentum in academia, this thesis might also help shed light on the caricatures of the oppressed in general, and those of the region of the Middle East in specific. More in-depth comparative studies related to the caricatures of Naji el-Ali with can be conducted in order to better understand his message of moral 
rebellion. Since academic studies related to Lebanese folklore remain scarce, this thesis can help shed better light on a rich folkloric heritage which needs to be explored more deeply. I meant for this thesis to be truly comparative in nature: East and West, Arabic and English, as well as dance, literature, and caricature in hopes of helping bridge what are regarded as opposites. 


\section{Works Cited}

Al-Beaini, Hassan Amin. Fūsul Min al-'adāt wal Taqālìd fì Lubnān. Lubnan: Matba'at Ghanem, 2009.

Al-Hajj, Ali, "Sīlah al-'ūyun.” A 'lam a-shi'r al- 'āmi fi Lubnān. Michel Khalil Jeha. (Beirut: Dar al- 'awdah, 2003) 210.

Al-Hashem, Joseph. "Lwatan Min Ba'd Allah.” A 'lam a-shi'r al- 'āmi fi Lubnān. Michel Khalil Jeha. (Beirut: Dar al- 'awdah, 2003) 222-223.

Al-Qari, Ameen. Rawa'e 'a Azzajal al-Lubnānī. Tripoli: Gros Press.

Asfour, Maamoun. "Naji Al-Ali Remembered.” Naji al-Ali.10 September 2001. 1 March 2009 <www.najielali.com>.

Banta, Martha. Barbaric Intercourse: Caricature and the Culture of Conduct, 1841-1936. Chicago: The University of Chicago Press, 2003.

Barthes, Roland. "The Death of the Author." Image Music Text. Trans. Stephen Heath. New York: Harper Collins, 1977.

Blesser, Barry, and Linda-Ruth Salter. Spaces Speak, Are You Listening? Experiencing Aural Architecture. Cambridge: The MIT Press, 2007.

Cachia, Pierre. Arabic Literature-An Overview. New York: RoutledgeCurzon, 2002.

Cancienne, Mary Beth, and Celeste N. Snowber. "Writing Rhythm: Movement as Method.” Qualitative Inquiry 9 (2003): 237-253.

Caricature Naji el-Ali. Beirut: Arab Doctrine Center, 2007.

Caruth, Cathy. Unclaimed Experience: Trauma, Narrative, and History. Baltimore, 1992.

Celtic Tiger. Dir. Michael Flatley. Perf. Michael Flatley. Universal Studios, 2005

Chodorow, Joan. Dance Therapy and Depth Psychology: The Moving Imagination. London: Routledge, 1991.

Coupe, W.A. “Observations on a Theory of Political caricature.” Comparative Studies in Society and History. 11 (1969): 79-95. 
Das, Santano. "War Poetry and the Realm of the Senses." The Oxford Handbook of British and Irish War Poetry, ed. Tim Kendall (Oxford: Oxford University Press, 2007) 7399.

Douglas, Roy, Liam Harte and Jim O’Hara. Drawing Conclusions: A Cartoon History of Anglo-Irish Relations Belfast: Blackstaff Press, 1998.

"Druid." Encyclopaedia Britannica. Encyclopadia Britannica Online. Encyclopædia Britannica, 2010. Web. 16 May $2010<$ http://www.search.eb.com/eb/ article9031248>.

El-Ali, Naji. "Tawr As-Sibā." Nājī el- 'Alī Kāmel at-Tūrāb al-Falastīnī: Min Ajli Hādha Qatalūnī. Tanqīh Mahmoud Abdullah Kulum. Beirut: Bisan Linnasher wattawzīa' wal-ia'lām, 2001.

El-Fassed, Arjan. "Naji al-Ali: The Timeless Conscience of Palestine." Naji al-Ali. 22 July 2004. 1 March 2009 <www.najialali.com>.

Foley, Kathrine. "Perceptions of Irish Step Dance: National, Global, and Local.” Dance Research Journal 33.1 (2001): 34-45.

Forrester, Michael. Psychology of the Image. London: Routledge, 2000.

Freud, Sigmund. The Standard Edition of the Complete Psychological Works of Sigmund Freud, Volume XIV (1914-1916): On the History of the Psycho-Analytic Movement, Papers on Metapsychology and Other Works. Trans. James Strachey. London: The Hogarth Press and the Institute of Psycho-analysis, 1957.

Ghabbash, Ghanem. "Haddadūni Bilqatel." Naji el-Ali: Al-Fannān, Al-Insān, Al-Qadiyya. Beirut: Markaz Naji el-Ali al-Thaqāfi, 1992.

Gill, Jo. Women's Poetry. Edinburgh: Edinburgh University Press, 2007.

Hanna, Judith Lynne. The Performer-Audience Connection: Emotion to Metaphor in Dance and Society. Austin: University of Texas, 1983.

Haurin, Don, and Ann Richens. "Irish Step Dancing: A Brief History.” 25 October 2009 
<http://www.geocities.com/aer_mcr/irdance/irhist.html>

Hollander, Joel. Coloured Political Lithographs as Irish Propaganda: Warrior Artists and the Battle for Home Rule, 1879-1886. Ceredigion: Edwin Mellen Press, 2007.

Hugo, Richard. "Richard Hugo.” Interview with David Dillon. Bellamy 101-13.

Jeha, Michel Khalil. A 'lām Ashi 'ir al- 'Ammi fi Lubnān. Beirut: Dar al-'Awdah, 2003.

Jung, Carl G. “The Transcendent Function.” Collected Works 6. Princeton: Princeton University Press, 1975.

Kemnitz, Thomas Milton. “The Cartoon as a Historical Source.” Journal of Interdisciplinary History. 4 (1973): 81-93

Khader, Lubna. "Naji al Ali: Immortal Palestinian Cartoonist.” Naji al-Ali. 26 August 1999. 01 March 2009 <www.najialali.com>.

Kinsella, Thomas. “The Divided Mind.” Irish Poets in English. Ed. Sean Lucy. Cork, 1972.

Kris, E. and E. Gombrich. “The Principles of Caricature”. British Journal of Medical Psychology. 8 (1938): 319-342.

Levine, Michael G. Writing Through Repression. Baltimore: The Johns Hopkins University Press, 1994.

Limbāshiri, Mustafa. "Wazīfat Fan al-Caricature al-Asās.. Naji el-Ali Namudhajan.” 1 May 2009. <http://www.ahewar.org/debat/show.art.asp?aid=76951>

Loverance, Rowena. Christian Art. London: The British Museum Press, 2007.

McDonald, Art. "How the Irish Became White.” 11 April 2010. <http://www.pitt.edu/ hirtle/uujec/white.html>

McGuckian, Medbh. "The Albert Chain.” Ed. Keith Tuma. Anthology of Twentieth-Century British and Irish Poetry. New York: Oxford University Press, 2001.

Miner, Thomas. “Tapeire.” 22 November 2009. <http://hornpipe.net/?p=790> Moody, Theo, and Frank Martin, ed. The Course of Irish History. Dublin: Mercier Press, 2001. 
Nikolopoulou, Kalliopi. "Feet, Fate, and Finitude: On Standing and Inertia in the Illiad." College Literature. 34.2 (2007): 174-193.

Ong, Walter Jackson. Orality and Literacy: The Technologizing of the Word. New York: Routledge, 2002.

Pease, Allan and Barbara. The Definitive Book of Body Language. New York: Bantam, 2004. Philips, Robert. The Confessional Poets. Carbondale: Southern Illinois UP, 1973.

Political Cartoon. 1 March $2009<\mathrm{http}: / / \mathrm{www}$.politicalcartoon.co.uk/html/history/dublinopinion.html>

Sarieddine, Khalil. Zajal Bilā Wajal. Beirut: Al-Markaz al-Arabi lil Abhāth wal Tawthīk, 1999.

Smith, Barbara Herrnstein. Poetic Closure: A Study of How Poems End. Chicago: The University of Chicago Press, 1968.

Streicher, Lawrence H. "David Low and the Sociology of Caricature." Comparative Studies in Society and History. 8 (1965): 1-23.

“Suppression.” Def. The American Heritage Dictionary of the English Language. $4^{\text {th }}$ ed. 2002.

“Taliban War on Women.” 30 April $2010<$ http://www.drabruzzi.com/taliban_war_on women. htm>

“Terrorist.” Def. The Oxford American Dictionary. Oxford University Press, 2001.

“The News.” Tele Liban. Beirut. 7 Mar. 2009.

Tuma, Keith, ed. Anthology of Twentieth-Century British and Irish Poetry. New York:

Oxford University Press, 2001.

Turner, Martyn. Figure 16. Pack up your troubles: 25 Years of Northern Ireland Cartoons. Belfast: Blackstaff Press, 1995.

Weber, Samuel. Legend of Freud. Minneapolis: University of Minnesota Press, 1982. 
Wechsler, Judith. “The Issue of Caricature.” Art Journal. 43 (1983): 317-318.

Yeats, William Butler. "To the Rose Upon the Rood of Time.” Anthology of TwentiethCentury British and Irish Poetry. Ed. Keith Tuma. New York: Oxford University Press, 2001.

Yeats, William Butler. "The Valley of the Black Pig." Ed. Keith Tuma. Anthology of Twentieth-Century British and Irish Poetry. New York: Oxford University Press, 2001. 